Pablo Cezar Urbieta

\title{
Gráficos CUSUM e EWMA para monitorar dados de contagem com distribuição Binomial Negativa
}



Pablo Cezar Urbieta

\section{Gráficos CUSUM e EWMA para monitorar dados de contagem com distribuição Binomial Negativa}

Dissertação apresentada à Escola Politécnica para obtenção do título de Mestre em Engenharia

Escola Politécnica da Universidade de São Paulo

Engenharia de Produção

Programa de Pós-Graduação em Engenharia de Produção

Orientador: Linda Lee Ho

São Paulo

2016 
Este exemplar foi revisado e corrigido em relação à versão original, sob responsabilidade única do autor e com a anuência de seu orientador.

São Paulo, de de

Assinatura do autor:

Assinatura do orientador:

Catalogação-na-publicação

Urbieta, Pablo Cezar

Gráficos CUSUM e EWMA para monitorar dados de contagem com distribuição Binomial Negativa / P. C. Urbieta -- versão corr. -- São Paulo, 2016. $64 \mathrm{p}$.

Dissertação (Mestrado) - Escola Politécnica da Universidade de São Paulo. Departamento de Engenharia de Produção.

1.Controle Estatístico do Processo 2.Gráfico de controle CUSUM 3.Gráfico de controle EWMA 4.Regressão Binomial Negativa I.Universidade de São Paulo. Escola Politécnica. Departamento de Engenharia de Produção II.t. 
Pablo Cezar Urbieta

\section{Gráficos CUSUM e EWMA para monitorar dados de contagem com distribuição Binomial Negativa}

Dissertação apresentada à Escola Politécnica para obtenção do título de Mestre em Engenharia

Aprovado em:

Banca Examinadora

Prof. Dr.:

Julgamento:

Prof. Dr.:

Julgamento:

Prof. Dr.:

Julgamento:
Instituição:

Assinatura:

Instituição:

Assinatura:

Instituição:

Assinatura:

São Paulo 



\section{Agradecimentos}

À $\operatorname{Prof}^{a}$. Dr ${ }^{a}$. Linda Lee Ho, por todo apoio, dedicação e orientação durante o desenvolvimento deste projeto.

Às Prof ${ }^{a s}$. Dr ${ }^{a s}$. Airlane Pereira Alencar e Celma de Oliveira Ribeiro, pelas sugestões e críticas dadas durante a Banca de Qualificação.

À Clarice Nazario do PRO-AIM, pela orientação para extração de dados diários utilizados neste projeto.

A todos meus gestores do Itaú, que fizeram ser possível conciliar a minha vida acadêmica e profissional.

À minha noiva e futura esposa Lilian, por todo o incentivo e por toda paciência nas (muitas) horas que precisei me dedicar a este trabalho.

À minha mãe Julia, que sempre foi um exemplo e fonte de inspiração para minha vida.

A Deus, criador de todas as coisas e que, sem Ele, nada faria sentido. 

"Você pode encarar um erro como uma besteira a ser esquecida, ou como um resultado que aponta uma nova direção" (Steve Jobs) 



\section{Resumo}

URBIETA, P. C. Gráficos CUSUM e EWMA para monitorar dados de contagem com distribuição Binomial Negativa. 2016. Dissertação (Mestrado) - Escola Politécnica, Universidade de São Paulo, São Paulo, 2016.

Gráficos de controle têm sido amplamente utilizados na manufatura para melhoria de processos. Diversas abordagens tem sido propostas para melhorar o desempenho dos gráficos existentes na literatura. Além disso, o uso de gráficos de controle tem se estendido para outras áreas, tais como, economia, finanças, medicina, etc. O objetivo deste trabalho é comparar o gráfico CUSUM com o gráfico EWMA para monitoramento do número diário de internações hospitalares. Para tanto, utilizou-se uma série histórica de internações devido a doenças respiratórias para a população acima de 65 anos. Um modelo linear foi ajustado considerando que o número de internações segue uma distribuição Binomial Negativa. São simulados diversos cenários de mudança no número médio de internações e utilizando diferentes estatísticas baseadas em transformações, é feita uma comparação entre estes gráficos. Verifica-se que o gráfico EWMA com limite de controle assintótico possui desempenho muito similar ao gráfico CUSUM. Já o EWMA implementado com limite de controle exato apresenta melhor desempenho em relação ao gráfico CUSUM quando se atribui pesos menores aos dados atuais.

Palavras-chaves: Controle Estatístico do Processo. Gráfico de controle CUSUM. Gráfico de controle EWMA. Regressão Binomial Negativa. 



\section{Abstract}

URBIETA, P. C. CUSUM and EWMA Control charts to monitor series of Negative Binomial count data. 2016. Dissertação (Mestrado) - Escola Politécnica, Universidade de São Paulo, São Paulo, 2016.

Control charts have been widely used for process improvement in manufacturing. In literature several approaches have been proposed to improve the current charts performance. In addition, the use of control charts has been extended to other areas such as economics, finance, medicine, and others. The objective of this study is to compare CUSUM control chart with EWMA control chart for monitoring daily number of hospital admissions. Using a historical hospitalizations series due to respiratory diseases for people over 65 years old, a Negative Binomial regression model is fitted. Several scenarios are simulated using different shifts in the mean and using different statistics based on transformations, in order to compare these charts. It is shown that EWMA control chart with asymptotic control limit has similar performance as CUSUM control chart. However, using smaller values for new observations the EWMA control chart with exact control limit has better performance than CUSUM control chart.

Key-words: Statistical Process Control. CUSUM Control Chart. EWMA Control Chart. Negative Binomial Model. 



\section{Lista de ilustrações}

Figura 1 - Elementos do Gráfico de Controle . . . . . . . . . . . . . . . . . . 25

Figura 2 - Limite Superior de Controle com Detecção Rápida. L = 1 . . . . . . . 33

Figura 3 - Internações diárias devido a doenças respiratórias para pessoas acimada de 65 anos na cidade de São Paulo entre 2006 a 2012 . . . . . . . . . . 37

Figura 4 - Internações diárias devido a doenças respiratórias para pessoas acimada de 65 anos na cidade de São Paulo em 2006 . . . . . . . . . . . . . . 38

Figura 5 - Etapas do processo de simulação . . . . . . . . . . . . . . 40

Figura 6 - Gráfico Quantil-Quantil para Resíduo da Desviância . . . . . . . . . . 44

Figura 7 - Internações diárias em São Paulo e valores ajustados . . . . . . . . . . 45

Figura 8 - Gráficos de Controle CUSUM e EWMA no histórico com método RS . 55

Figura 9 - Gráficos de Controle CUSUM e EWMA no histórico com método JK · 56

Figura 10 - Gráficos de Controle CUSUM e EWMA no histórico com método GN . 56

Figura 11 -Gráficos de Controle CUSUM e EWMA no histórico com método JG · 56

Figura 12 -Gráficos de Controle CUSUM e EWMA no histórico com método DR . 57

Figura 13 -Gráficos de Controle CUSUM e EWMA no histórico com método RY . 57

Figura 14 -Gráficos de Controle CUSUM e EWMA no histórico com método LR . 57

Figura 15 -Comparação da taxa de internação de 2011 com anos anteriores . . . . 58 



\section{Lista de tabelas}

Tabela 1 - Estimativas, erros padrão e valores-p correspondentes aos parâmetros do modelo . . . . . . . . . . . . . . . . . . . . 43

Tabela 2 - Parâmetros $k$ e $h$ para gráfico CUSUM . . . . . . . . . . . 46

Tabela 3 - $A R L_{1}$ para gráficos EWMA com limite assintótico (LSC independente

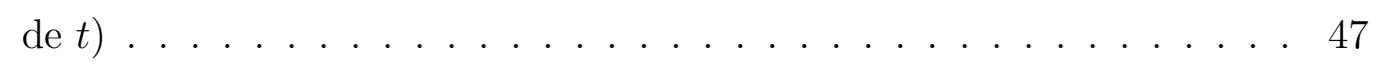

Tabela 4 - $A R L_{1}$ para gráficos EWMA com limite de controle exato (LSC depen-

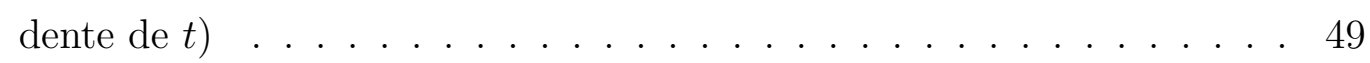

Tabela 5 - Comparação EWMA - $A R L_{1}$ do LSC exato menos $A L R_{1}$ do LSC assintótico . . . . . . . . . . . . . . . . . 51

Tabela 6 - Comparativo de $A R L_{1}$ dos gráficos CUSUM e EWMA com limite assintótico . . . . . . . . . . . . . . . . . 52

Tabela 7 - Comparativo de $A R L_{1}$ dos gráficos CUSUM e EWMA com limite de controle exato . . . . . . . . . . . . . . . 53 



\section{Lista de abreviaturas e siglas}

ARL Average Run Length (Número Médio de Amostras Necessárias)

CEP Controle Estatístico do Processo

CEQ Controle Estatístico da Qualidade

CUSUM Cumulative Sum (Soma Cumulativa)

DR Transformação baseada no Resíduo da Desviância (Deviance Residual)

EWMA Exponentially Weighted Moving Average (Média Móvel Exponencialmente Ponderada)

GN Tranformação proposta por Guan

JG Tranformação proposta por Jorgensen

JK Transformação proposta por Johnson, Kemp e Kotz

LR Método baseado na Razão Verossimilhança (Likelihood Ratio)

LSC Limite Superior de Controle

MLG Modelos Lineares Generalizados

RS Transformação proposta por Rossi, Lampugnani e Marchi

RY Método proposto por Rogerson e Yamada 



\section{Sumário}

Introdução . . . . . . . . . . . . . . . . . . . 21

I Revisão de Literatura $\quad 23$

1 Gráficos de Controle . . . . . . . . . . . . . . . . . . . . . . . . 25

1.1 Visão Geral . . . . . . . . . . . . . . . . . . . . 25

1.2 Controle Estatístico do Processo na Área da Saúde . . . . . . . . . . . . . 27

1.3 Gráficos de Controle para Monitorar Série de Contagem . . . . . . . . . . . 28

1.4 CUSUM . . . . . . . . . . . . . . . . . . . . 30

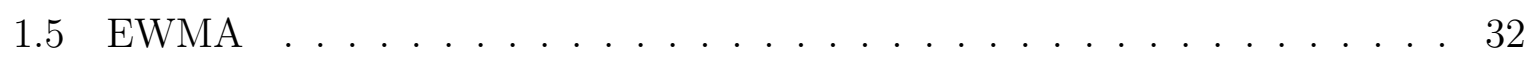

II Metodologia 35

2 Materiais e Método . . . . . . . . . . . . . . . . 37

2.1 Dados . . . . . . . . . . . . . . . . . . . 37

2.2 Modelo. . . . . . . . . . . . . . . . . . . . . . . . . . 38

2.3 Simulação de cenários . . . . . . . . . . . . . . . . . . . . 39

III Resultados $\quad 41$

3 Resultados. . . . . . . . . . . . . . . . . . . . . . 43

3.1 Ajuste do Modelo . . . . . . . . . . . . . . . . . 43

3.2 Desempenho dos Gráficos de Controle . . . . . . . . . . . . . . . 44

3.3 Aplicação dos Gráficos nos Dados Históricos . . . . . . . . . . . . . . . . 55

Conclusões . . . . . . . . . . . . . . . . . . . . . . . 59

Referências ............................ . 61

$\begin{array}{ll}\text { Anexos } & 65\end{array}$

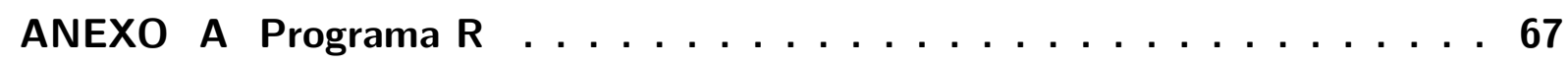





\section{Introdução}

Segundo Woodall (2000), métodos estatísticos são vitais na melhoria de processos de manufatura e serviços. O Controle Estatístico do Processo (CEP), uma sub-área do Controle Estatístico da Qualidade (CEQ), consiste em entender, monitorar e melhorar processos ao longo do tempo.

O controle e melhoria da qualidade tem se tornado importante para diversas organizações, desde indústrias, empresas de transportes, órgãos de saúde, organizações financeiras e agências governamentais (MONTGOMERY, 2009). Assim, o uso de gráficos de controle tem se expandido para outras áreas além do seu uso original na manufatura.

Recentemente o CEP também tem sido aplicado em problemas de monitoramento na saúde pública (ALENCAR et al., 2015; WOODALL, 2006) e as abordagens mais recentes propõem detectar surtos de doenças infecciosas.

Alencar et al. (2015) propuseram a utilização de Gráficos de Controle da Soma Cumulativa (em inglês, CUSUM - Cumulative Sum) para monitorar taxas de internações devido a doenças respiratórias em pessoas com idade acima de 65 anos na cidade de São Paulo. Foi ajustado um modelo com distribuição Binomial Negativa empregando uma função de ligação logarítmica, foi utilizado o tamanho da população como offset e um conjunto de covariáveis.

Aplicando uma série de transformações propostas na literatura, foram simulados diversos cenários de mudanças no número médio de internações. Assim, foi possível medir o desempenho de cada uma das transformações em termos do número médio de amostras necessárias (em inglês, $A R L$ - average run length) até a sinalização que o processo está fora de controle.

O presente projeto pode ser visto como uma extensão do trabalho de Alencar et al. (2015). Para o mesmo conjunto de dados históricos e as mesmas transformações propostas, foi aplicado o Gráfico de Controle de Média Móvel Exponencialmente Ponderada (em inglês, EWMA - Exponentially Weighted Moving Average) para os cenários avaliados por Alencar et al. (2015) e é feita uma comparação do desempenho entre os dois tipos de gráficos de controle, CUSUM e EWMA.

Este trabalho é estruturado conforme descrito a seguir. No Capítulo I é apresentada uma revisão da literatura sobre Gráficos de Controle, sua aplicação na área da saúde e para séries de dados de contagem. No Capítulo II são apresentados os dados utilizados para o desenvolvimento do trabalho, o ajuste do modelo para a simulação dos cenários e é feita uma comparação entre os dois tipos de gráficos. Por fim, no Capítulo III são 
apresentados os resultados e as conclusões deste projeto. 


\section{Parte I}

Revisão de Literatura 



\section{Gráficos de Controle}

\subsection{Visão Geral}

Gráficos de controle são amplamente utilizados no monitoramento de processos e serviços. Estes consistem em uma exibição gráfica de uma característica de qualidade medida a partir de amostras ou ao longo do tempo (MONTGOMERY, 2009). A Figura 1 apresenta os elementos de um gráfico de controle. Este é composto por uma linha central (LC), que corresponde à média da característica monitorada, e duas linhas horizontais chamadas de Limite Superior de Controle (LSC) e Limite Inferior de Controle (LIC). Em processos sob controle, a maior parte das amostras estará entre estes dois limites.

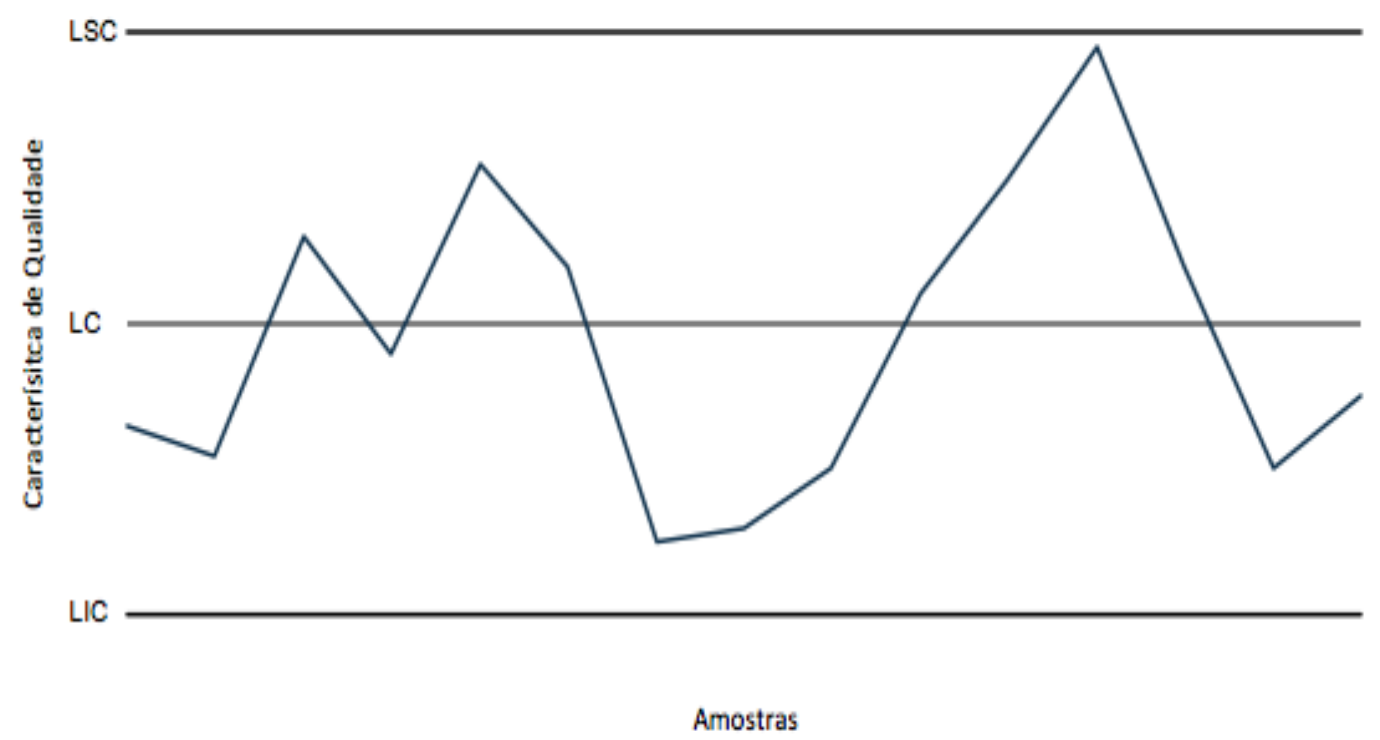

Figura 1: Elementos do Gráfico de Controle

No entanto, nem sempre são utilizados os dois limites de controle, LSC e LIC. Em certas aplicações pode haver a preocupação em monitorar se há aumento no parâmetro de interesse e serão considerados fora de controle somente pontos acima do limite superior. Em outras aplicações a preocupação pode ser com uma diminuição no parâmetro de interesse e o processo será considerado fora de controle se houver pontos abaixo do limite inferior. Neste projeto, por exemplo, o objetivo é monitorar surtos de doenças respiratórias, ou seja, se o número médio de internações aumentou. Assim, o gráfico de controle é calibrado para detectar aumento na média, sendo utilizado apenas o LSC.

Um sinal ocorre quando o valor da característica monitorada fica acima do limite superior ou abaixo do limite inferior e é um indicativo que o processo pode estar fora 
de controle. Deve-se então investigar e corrigir, se necessário, as causas do desvio do processo. Segundo Woodall (2000), uma variação de "causa comum" ocorre em decorrência da natureza do processo e não pode ser alterada sem uma modificação no processo. Já uma "causa especial" ocorre devidos a choques não usuais ou rupturas no processo, cujas causas devem ser removidas. Um dos propósitos do gráfico de controle é distinguir estes dois tipos de variação de forma a prevenir uma reação precoce ou tardia.

É importante ressalvar que, mesmo que todos os pontos estejam entre os limites de controle, não necessariamente o processo estará sob controle. Por exemplo, se ocorrem muitos pontos sequenciais acima ou abaixo da linha central, pode ser um indicativo que houve alguma mudança no processo e que precisa ser investigada.

Para construir um gráfico de controle Shewhart, considere a característica da qualidade e supondo que a média e o desvio padrão são respectivamente $\mu_{x}$ e $\sigma_{x}$, o limite central, superior e inferior são dados pela Equação (1.1):

$$
\begin{aligned}
& L S C=\mu_{x}+L \sigma_{x} \\
& L C=\mu_{x} \\
& L I C=\mu_{x}-L \sigma_{x}
\end{aligned}
$$

onde $L$ é a distância dos limites de controle da linha central, expressa em unidades do desvio padrão.

Diversas abordagens tem sido propostas na literatura para melhorar o desempenho dos gráficos de controle. Woodall (2000) afirma que tem sido demonstrado que os gráficos de Soma Cumulativa (CUSUM) e Média Móvel Exponencialmente Ponderada (EWMA) são muito mais eficazes do que cartas de Shewhart em detectar mudanças contínuas de pequeno e médio porte nos parâmetros da distribuição de probabilidade de uma característica de qualidade.

O desempenho de um gráfico de controle pode ser medido pela rapidez com que "causas especiais" são detectadas. Uma forma de avaliação é através do ARL (Average Run Length), que é número médio de amostras necessárias até a sinalização que o processo está fora de controle. Se as observações são independentes, o ARL pode ser calculado por:

$$
A R L=\frac{1}{p}
$$

onde $p$ é a probabilidade de qualquer amostra exceder os limites de controle.

Se o processo está sob controle, é desejável que o número médio de amostras até a sinalização, $A R L_{0}$, seja grande. Para um gráfico de controle que tem uma probabilidade $p$ igual a $0.2 \%$, o $A R L_{0}$ será igual a 500 . Caso o processo esteja fora de controle, o número médio de amostras $\left(A R L_{1}\right)$ deve ser o menor possível. Geralmente, para se comparar o 
desempenho entre diferentes tipos de gráfico, estes são calibrados de forma a terem $A R L_{0}$ iguais ou muito próximos e avalia-se qual destes tem menor $A R L_{1}$ quando o processo está fora de controle. Geralmente, esta avaliação é feita via Cadeia de Markov (BROOK; EVANS, 1972) e/ou via simulação.

\subsection{Controle Estatístico do Processo na Área da Saúde}

Woodall e Montgomery (2014) dividem as aplicações do Controle Estatístico na área da saúde em três grandes tópicos: monitoramento dos serviços de saúde, vigilância da saúde pública e vigilância de síndromes.

No monitoramento dos serviços de saúde, existem muitas variáveis que podem ser controladas, como infecções adquiridas em hospitais, taxa de quedas por pacientes, taxa de erros em prescrições, entre outros. Em muitas aplicações, o evento de interesse é binário. Aplicações que tratam destas questões podem ser consultadas em Nelson (1994), Steiner et al. (2000), Casey et al. (2001), Grigg e Farewell (2004), Thor et al. (2007), Tennant et al. (2007), Winkel e Zhang (2007), Woodall et al. (2008), Gandy et al. (2010), Szarka e Woodall (2011), Faltin et al. (2012) e Santiago e Smith (2013).

Na vigilância da saúde pública, em geral, o interesse está em monitorar doenças ou taxas de mortalidade. Para Woodall e Montgomery (2014), a vigilância da saúde pública oferece mais desafios do que se encontra no monitoramento em indústrias.

Em dados de saúde pública, deve-se levar em consideração o efeito do dia da semana, que raramente é visto em aplicações industriais. Para doenças infecciosas como a influenza, efeitos sazonais irregulares pode ser encontrados. Em outros casos, como doenças respiratórias presente neste projeto, padrões de sazonalidade devem ser considerados, uma vez que mais internações são esperadas nos meses mais frios. Segundo Woodall (2006) e Unkel et al. (2012) diversos métodos têm sido propostos dentro da vigilância da saúde pública para detectar pequenas mudanças.

Outra diferença apontada por Woodall (2006) é que em aplicações de saúde, ao contrário das aplicações industriais em geral, não é possível ajustar o processo e retornar para o estado sob-controle. Em muitas aplicações na saúde, o gráfico de controle pode continuar a emitir alertas após o primeiro alerta e mesmo após ações para correção do processo.

Outro desafio nesta área é que, aqueles que coletam e reportam os dados não são aqueles que fazem a análise, podendo levar a atrasos na obtenção de dados, erros de gravação e armazenagem e dados faltantes.

Além disso, existem mais fontes de variabilidade nos dados da saúde pública do que em dados de indústrias. Adicionalmente, Woodall e Montgomery (2014) detalham 
outros desafios que podem ser encontrados nesta área como dados autocorrelacionados, monitoramento espaço temporal e condições transientes "fora-de-controle".

Na vigilância da saúde pública, há um foco em encontrar algoritmos mais eficientes em detectar surtos, como é o caso do presente projeto.

Na vigilância de síndromes, dados de diferentes fontes são combinadas para detectar bioterrorismo ou surtos de doenças. Por exemplo, podem ser considerados dados de vendas de remédios sem prescrição, taxa de absenteísmo e entradas em sala de emergência para obter um alerta de ataque ou surto. Este tópico poderia ser considerado uma categoria da vigilância da saúde pública, mas Woodall e Montgomery (2014) preferem classificar como um tópico específico. Descrições mais detalhadas de vigilância de síndromes podem ser encontradas em Fricker Jr. (2013) e Lombardo et al. (2003). Complicações e questões desta área foram revisadas por Buckeridge et al. (2005), Fricker Jr. e Rolka (2006), Shmueli e Burkom (2010), Fricker Jr. (2011) e Kman e Bachmann (2012).

\subsection{Gráficos de Controle para Monitorar Série de Contagem}

Para Höhle e Paul (2008), dados de contagem na vigilância da saúde pública têm características específicas que métodos do CEP não tratam e que precisam de soluções especiais, como utilizar informações de covariáveis (por exemplo, variações sazonais na média), ajuste do tamanho da população e outras variáveis. Basicamente, os autores propõem utilizar gráficos de regressão baseados em Modelos Lineares Generalizados (MLG). Gráficos de regressão com variável resposta normal podem ser encontrados em Basseville et al. (1993), Lai (1995) e Lai e Shan (1999). Gráficos de controle baseados em MLG podem ser encontrados em aplicações de engenharia em Skinner et al. (2003) e na literatura de vigilância da saúde em Rossi et al. (1999) e Rogerson e Yamada (2004).

Usualmente, utiliza-se a distribuição de Poisson para modelos de série de contagem (ROSSI, 2010), mas recentemente, a distribuição Binomial Negativa tem sido utilizada (HÖHLE; PAUL, 2008). Em geral, os artigos constroem os gráficos de controle propondo variáveis transformadas para normalizar os dados de contagem e depois os limites são calculados baseados em distribuições Gaussianas (ROSSI, 2010; ROSSI et al., 1999). A premissa de normalidade, embora importante, usualmente não é verificada na maioria das análises (ALENCAR et al., 2015).

Com o objetivo de construir gráficos de controle para monitorar série de contagem, Alencar et al. (2015) consideram as seguintes premissas:

- Somente uma observação $X_{t}$ está disponível no tempo $t$ e $X_{t}$ assume somente valores inteiros não negativos em $\{0,1, \ldots$,$\} ;$

- O valor esperado pode variar ao longo do tempo em função de variáveis explicativas; 
- $X_{t}$ segue distribuição de Poisson ou Binomial Negativa.

O valor esperado de $X_{t}$ quando o processo está sob controle será denotado por $\mu_{0, t}$ e quando o processo está fora de controle será denotado por $\mu_{1, t}$. Observa-se que mesmo para o processo sob controle, o valor esperado pode variar ao longo do tempo.

A função de probabilidade de $X_{t}$ seguindo uma função de Poisson, escrita como membro de uma família exponencial, é

$$
f\left(X_{t} \mid \mu_{t}\right)=\exp \left\{X_{t} \ln \mu_{t}-\mu_{t}-\ln \left(\Gamma\left(X_{t}+1\right)\right)\right\}
$$

com $E\left(X_{t}\right)=\operatorname{Var}\left(X_{t}\right)=\mu_{t}$. A função gama é uma extensão da função fatorial e para valores inteiros positivos, tem-se $\Gamma(n)=(n-1)$ !.

Já na distribuição Binomial Negativa, a média pode ser diferente da variância e possui um coeficiente de variação $1+\mu / \phi$ (HARDIN et al., 2007). Assim, a função Binomial Negativa é escrita como:

$$
f\left(X_{t} \mid \mu_{t}, \phi\right)=\exp \left\{X_{t} \ln \left(\frac{\mu_{t}}{\mu_{t}+\phi}\right)+\phi \ln \left(\frac{\mu_{t}}{\mu_{t}+\phi}\right)+\ln \left(\frac{\Gamma\left(\phi+X_{t}\right)}{\Gamma\left(X_{t}+1\right) \Gamma(\phi)}\right)\right\}
$$

$\operatorname{com} E\left(X_{t}\right)=\mu_{t}$ e $\operatorname{Var}\left(X_{t}\right)=\mu_{t}+\mu_{t}^{2} / \phi$

Conforme descrito anteriormente, para monitorar dados não-normais, geralmente são aplicadas transformações nos dados originais com o objetivo de se obter uma distribuição aproximadamente normal. A seguir são apresentadas as transformações usadas por Alencar et al. (2015) para aplicação dos gráficos CUSUM e para a aplicação dos gráficos EWMA deste projeto.

A primeira transformação de Rossi et al. (1999), que será chamada pela sigla $\mathrm{RS}$, propõe uma estatística que segue uma distribuição assintótica normal padronizada apresentada na Equação (1.3).

$$
Z_{R S, t}=\frac{X_{t}-3 n_{t} \mu_{t}+2 \sqrt{X_{t} n_{t} \mu_{t}}}{2 \sqrt{n_{t} \mu_{t}}}
$$

De maneira similar Johnson et al. (2005) propuseram uma transformação para uma sequência de $X_{t}$ com o objetivo de estabilizar a variância e é expressa por:

$$
Z_{J K, t}=\sqrt{\phi-a}\left(\operatorname{senh}^{-1} \sqrt{\frac{X_{t}+b}{\phi-2 b}}-\operatorname{senh}^{-1} \sqrt{\frac{u_{t}+b}{\phi-2 b}}\right)
$$

com $a=b=0$ ou $a=0.5$ e $b=0.375$. 
Outra transformação proposta foi sugerida por Yu (2009):

$$
Z_{G N, t}=\sqrt{\phi-0.5}\left(\sqrt{\frac{X_{t}+0.385}{\phi-0.75}}-\sqrt{\frac{\mu_{t}+0.385}{\phi-0.75}}\right)
$$

Já Jorgensen (1997) propõe a padronização de dados de contagem $X_{t}$ para dados binomiais negativos expressa como:

$$
Z_{J G, t}=\frac{X_{t}-\mu_{t}}{\sqrt{\phi \pi_{t} /\left(1-\pi_{t}\right)^{2}}}
$$

$\operatorname{com} \pi_{t}=\mu_{t} /\left(\mu_{t}+\phi\right)$.

Outra abordagem é utilizar gráficos de controle com resíduos padronizados obtidos após ajustar um modelo linear generalizado para dados de contagem. O Resíduo da Desviância, do termo em inglês Deviance Residual (PAULINO et al., 2011), por apresentar variância estável e por seguir uma distribuição normal padronizada (MCCULLOCH; NEUHAUS, 2001; MCCULLAGH; NELDER, 1989) é um candidato para ser utilizada no monitoramento do gráfico de controle.

O Resíduo da Desviância para uma distribuição Binomial Negativa é:

$$
Z_{D R, t}=\operatorname{sign}\left(X_{t}-\mu_{t}\right) \sqrt{\left(d_{t}^{2}\right)}
$$

com

$$
d_{t}^{2}= \begin{cases}2 \phi \ln \left(1+\mu_{t} / \phi\right) & \text { se } X_{t}=0 \\ 2 X_{t} \ln \left(\frac{X_{t}}{\mu_{t}}\right)-2 \phi\left(1+X_{t} / \phi\right) \ln \left(\frac{1+X_{t} / \phi}{1+\mu_{t} / \phi}\right) & \text { se } X_{t}>0\end{cases}
$$

conforme definido por Hardin et al. (2007). Segundo McCulloch e Neuhaus (2001), $Z_{D R, t}$ segue aproximadamente uma distribuição normal.

Ainda serão apresentadas mais dois métodos utilizados neste projeto. Porém, o entendimento destas é mais claro ao se compreender a construção do gráfico CUSUM.

\subsection{CUSUM}

As estatísticas apresentadas nas Equações de (1.3) a (1.7) são utilizadas para construir o gráfico de controle CUSUM, conforme apresentado a seguir:

$$
C_{i, t}=\max \left(0, C_{i, t-1}+Z_{i, t}-k_{i, t}\right), i=\{\mathrm{RS}, \mathrm{JK}, \mathrm{GN}, \mathrm{JG} \text { e DR }\}
$$

O termo $k_{t}$ é geralmente considerando constante ao longo tempo. Se $C_{i, t}>h_{i}$ indica-se que o processo pode estar fora de controle. 
Segundo Rogerson e Yamada (2004), resultados equivocados podem ser obtidos se o gráfico CUSUM for implementado com parâmetros fixos quando a taxa média não for constante entre períodos distintos. Assim, eles propuseram um gráfico de controle CUSUM para dados com distribuição Poisson com parâmetros $k_{t}$ e $h_{t}$ que variam ao longo do tempo para detectar mudanças de dados temporais com efeitos sazonais. O gráfico proposto é apresentado a seguir:

$$
C_{R Y, t}=\max \left(0, C_{R Y, t-1}+c_{t}\left(X_{t}-k_{t}\right)\right)
$$

Expressões para séries $k_{t}$ para diversas distribuições da família exponencial, incluindo as distribuições Poisson e Binomial Negativa, podem ser encontradas em Hawkins e Olwell (2012). Fixando $c_{t}$ igual a 1 na Equação (1.9), Alencar et al. (2015) usaram a seguinte estatística para monitorar os dados de contagem com o valor de $k_{t}$ :

$$
k_{t}=\frac{-\phi \ln \left\{\left(\phi+\mu_{0, t}\right) /\left(\phi+\mu_{1, t}\right)\right\}}{\ln \left\{\mu_{1, t}\left(\phi+\mu_{0, t}\right) / \mu_{0, t}\left(\phi+\mu_{1, t}\right)\right\}}
$$

Assim, usando a notação das transformações anteriores, a variável monitorada na Equação (1.8) usada em Alencar et al. (2015) é:

$$
Z_{R Y, t}=X_{t}-\frac{-\phi \ln \left\{\left(\phi+\mu_{0, t}\right) /\left(\phi+\mu_{1, t}\right)\right\}}{\ln \left\{\mu_{1, t}\left(\phi+\mu_{0, t}\right) / \mu_{0, t}\left(\phi+\mu_{1, t}\right)\right\}}
$$

E o gráfico de controle CUSUM para esta transformação é equivalente ao apresentado na Equação (1.8) e o processo está fora de controle se $C_{R Y, t}>h$.

A última estatística proposta utiliza a abordagem de Höhle e Paul (2008) baseada na razão de verossimilhanças (em inglês, likelihood ratio). Esta estatística corresponde a testar a hipótese nula de que todas as observações vem da mesma distribuição sobcontrole, contra a hipótese alternativa que as observações $\tau, \ldots, n$ vem de um processo fora de controle conforme mostrado abaixo:

$$
N=\min \left\{n \geq 1: \max _{1 \leq \tau \leq n}\left[\ln L(\tau)=\sum_{t=\tau}^{n} \ln \left\{\frac{f\left(x_{t} \mid \mu_{1, t}, \phi, w_{t}\right)}{f\left(x_{t} \mid \mu_{0, t}, \phi, w_{t}\right)}\right\}\right] \geq h\right\}
$$

onde $w_{t}$ são covariáveis, $\phi$ é o parâmetro de dispersão e $f\left(x_{t} \mid \mu_{t}, \phi, w_{t}\right)$ é a função densidade de probabilidade da distribuição Binomial Negativa conforme definido na Equação (1.2).

A transformação baseada neste teste de hipótese é dada por:

$$
Z_{L R, t}=\ln \left\{\frac{f_{\theta_{0}}\left(x_{t}\right)}{f_{\theta_{1}}\left(x_{t}\right)}\right\}
$$


Novamente, a transformação acima é utilizada com o gráfico CUSUM da Equação (1.8) e com $C_{L R, 0}=0$.

\subsection{EWMA}

A Média Móvel Exponencialmente Ponderada (em inglês EWMA, Exponentially Weighted Moving Average) é muito efetiva na detecção de pequenas mudanças no processo (MONTGOMERY, 2009). Esta é definida como:

$$
Y_{t}=\lambda Z_{t}+(1-\lambda) Y_{t-1}
$$

onde $0<\lambda \leq 1$ é uma constante e o valor inicial de $Y_{0}$ é o valor alvo (MONTGOMERY, 2009; ROBERTS, 1959).

Os limites de controle para o gráfico EWMA são definidos conforme a Equação (1.15):

$$
\begin{aligned}
& L S C=\mu_{0}+L^{*} \sigma \sqrt{\frac{\lambda}{2-\lambda}\left[1-(1-\lambda)^{2 t}\right]}, \\
& L C=\mu_{0}, \\
& L S C=\mu_{0}-L^{*} \sigma \sqrt{\frac{\lambda}{2-\lambda}\left[1-(1-\lambda)^{2 t}\right]}
\end{aligned}
$$

onde $L^{*}$ é o fator que determina a amplitude do limite de controle e $\sigma$ é o desvio padrão da variável monitorada.

O termo $(1-\lambda)^{2 t}$ se aproxima de zero se $t$ tende a infinito. Montgomery (2009) recomenda fortemente utilizar os limites de controle conforme definidos na Equação (1.15) para valores pequenos de $t$. Isto melhorará o desempenho do gráfico de controle em detectar amostras fora de controle logo que o monitoramento do EWMA for iniciado.

Em geral, espera-se que quanto menor o valor de $\lambda$, mais rapidamente ele irá detectar pequenos desvios. Quanto maior o valor de $\lambda$, menor o peso que os dados históricos tem no cálculo de $Y_{t}$ e para $\lambda=1$ o gráfico EWMA é igual ao gráfico de Shewhart (COSTA et al., 2013).

Neste projeto, o gráfico de controle, a ser denominado por EWMA com limite de controle exato, foi aplicado conforme apresentado a seguir:

$$
Y_{i, t}=\lambda Z_{i, t}+(1-\lambda) Y_{i, t-1} \quad i=\{\mathrm{RS}, \mathrm{JK}, \mathrm{GN}, \mathrm{JG}, \mathrm{DR}, \mathrm{RY} \text { e LR }\}
$$




$$
L S C_{i}=E\left(Z_{0}\right)+L_{i} \sqrt{\left[1-(1-\lambda)^{2 t}\right]} i=\{\mathrm{RS}, \mathrm{JK}, \mathrm{GN}, \mathrm{JG}, \mathrm{DR}, \mathrm{RY} \text { e LR }\}
$$

onde $E\left(Z_{0}\right)$ é o valor esperado das transformações apresentadas nas Equações (1.3), (1.4), (1.5), (1.6), (1.7), (1.11) e (1.13) sob $H_{0}, L_{i}$ define a amplitude do gráfico de controle e o termo $\sqrt{\left[1-(1-\lambda)^{2 t}\right]}$ permite a rápida detecção de amostras fora de controle para $t \mathrm{~s}$ pequenos. Se $Y_{i, t}>L S C_{i}$ indica-se que o processo está fora de controle.

A Figura 2 mostra o efeito do termo $\sqrt{\left[1-(1-\lambda)^{2 t}\right]}$ no comportamento do LSC para diversos valores de $\lambda$ e $L=1$.

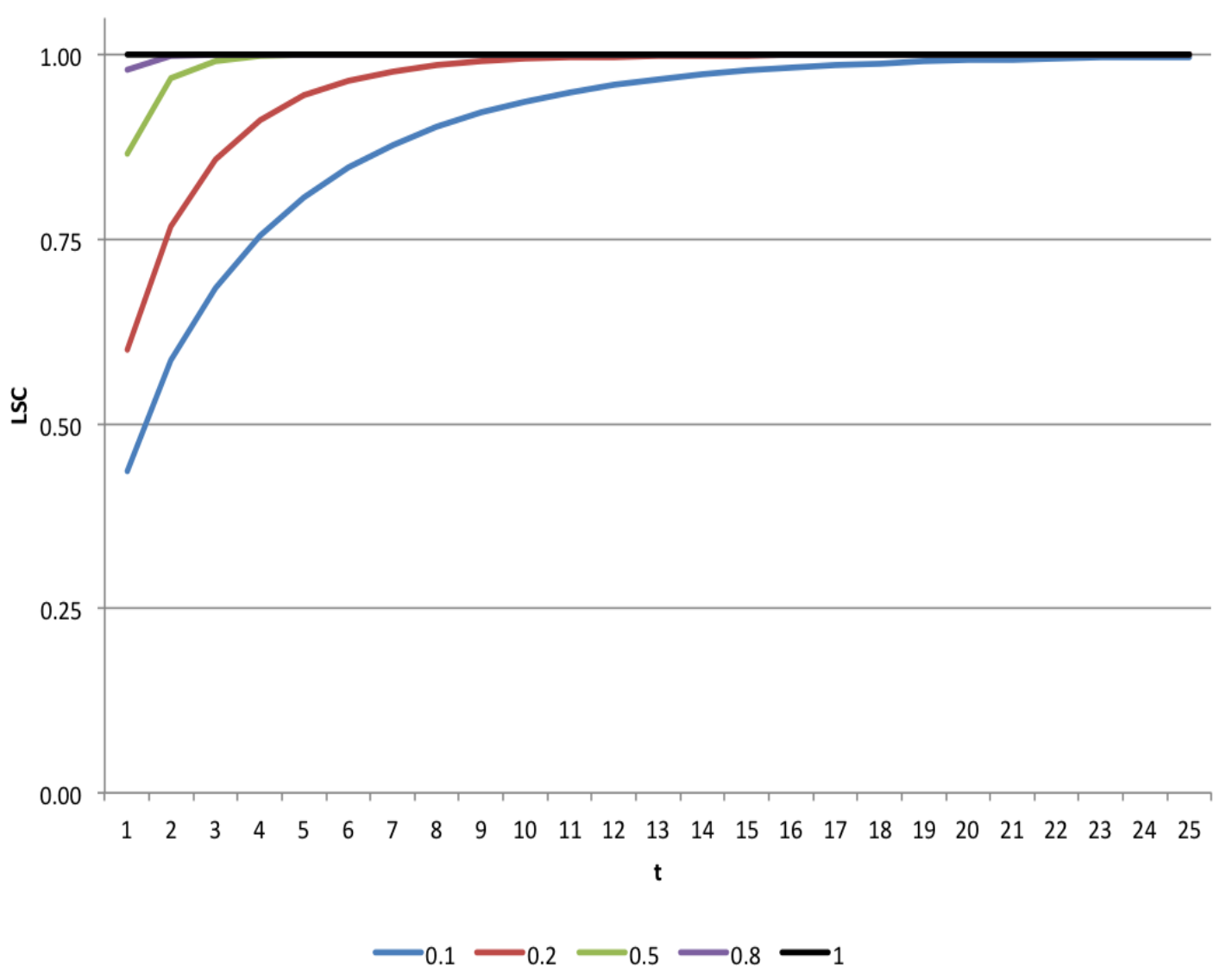

Figura 2: Limite Superior de Controle com Detecção Rápida. L = 1

Observa-se que, quanto menor o valor de $\lambda$, menor o valor do LSC para os valores iniciais de $t$. Além disso, quanto menor o $\lambda$, mais tempo leva para o LSC se aproximar do valor assintótico 1 . Por exemplo, para $\lambda$ igual a 0.8 , a diferença entre o valor assintótico e 1 é menor que 0.01 quando $t=2$. Para $\lambda$ igual a 0.1 , essa diferença só é menor que 0.01 para $t=19$. Finalmente, para $\lambda=1$, o LSC permanece constante igual a 1 .

Por simplicidade e facilidade, muitas vezes é utilizado apenas o gráfico EWMA com limite de controle assintótico, ou seja, sem o termo $\sqrt{\left[1-(1-\lambda)^{2 t}\right]}$, conforme apresentado 
na Equação (1.18).

$$
L S C_{i}=E\left(Z_{0}\right)+L_{i} \quad i=\{\mathrm{RS}, \mathrm{JK}, \mathrm{GN}, \mathrm{JG}, \mathrm{DR}, \mathrm{RY} \text { e LR }\}
$$

$E\left(Z_{0}\right)$ é o valor esperado das transformações apresentadas Equações (1.3), (1.4), (1.5), (1.6), (1.7), (1.11) e (1.13) sob $H_{0}$ e $L$ define a amplitude do gráfico de controle. Novamente, se $Y_{i, t}$ for maior que $L S C_{i}$ indica-se que o processo está fora de controle. 
Parte II

Metodologia 



\section{Materiais e Método}

Nesse capítulo são apresentados os materiais e método utilizados para o desenvolvimento deste projeto. São descritos os dados utilizados, o modelo probabilístico e as covariáveis usadas para o ajuste das informações históricas e o método e as etapas da simulação para avaliação do desempenho dos gráficos de controle.

\subsection{Dados}

Para o desenvolvimento deste projeto, foi utilizada uma série histórica de dados diários de contagem devido a doenças respiratórias para pessoas acima de 65 anos na cidade de São Paulo entre Janeiro de 2006 a Dezembro de 2012. Foi utilizado este período para ser possível ajustar o mesmo modelo e comparar os resultados com o trabalho anterior de Alencar et al. (2015). A Figura 3 apresenta o histórico da taxa de internações da população com 65 anos ou mais obtido do Sistema de Informações Hospitalares da Secretaria Municipal de Saúde de São Paulo.

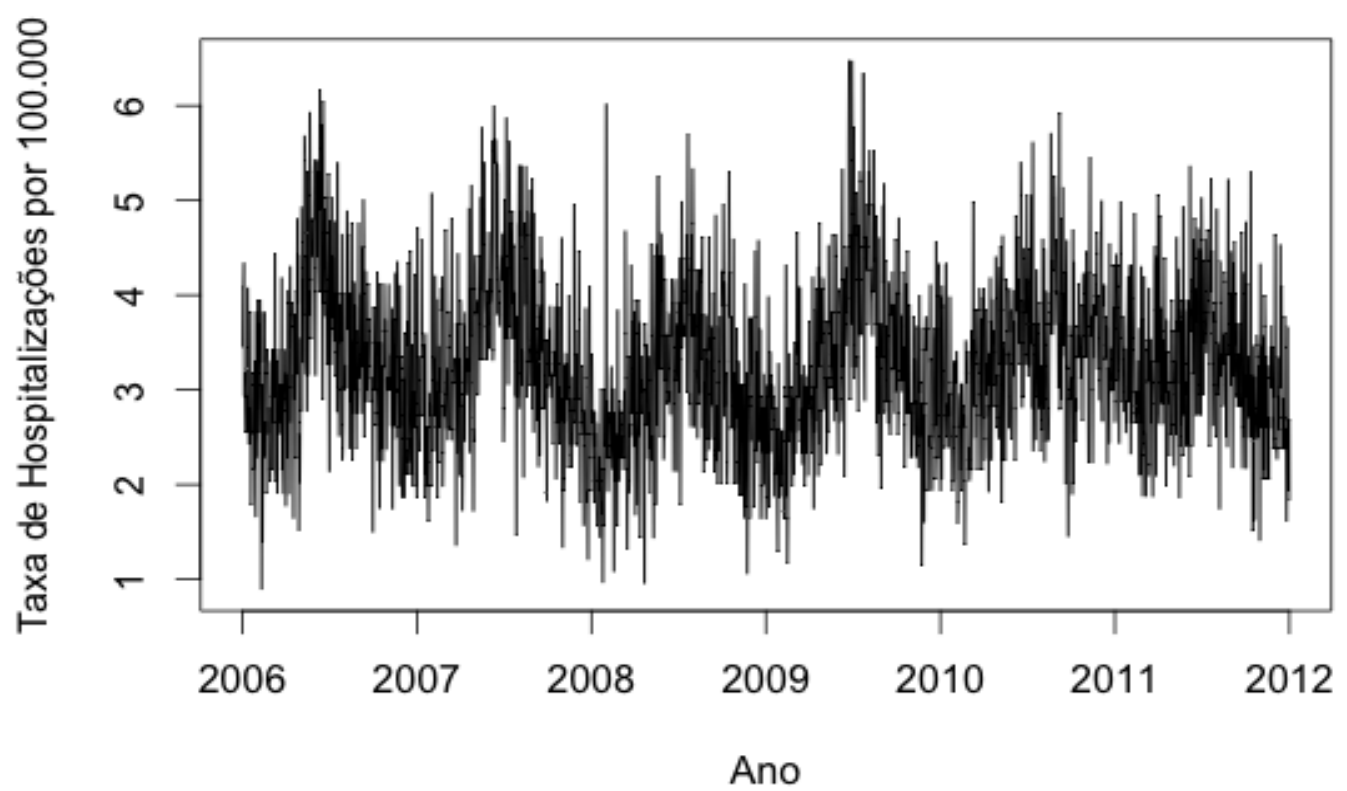

Figura 3: Internações diárias devido a doenças respiratórias para pessoas acimada de 65 anos na cidade de São Paulo entre 2006 a 2012

Como pode ser observado, a taxa histórica é estável ao longo do tempo e possui sazonalidade anual. Em geral, nos meses mais frios (entre junho a agosto) em São Paulo 
ocorrem mais internações quando comparado ao meses mais quentes. A Figura 4 apresenta o histórico de dados apenas para o ano de 2006 em que é mais fácil perceber a sazonalidade. Além da sazonalidade ao longo do ano, através do ajuste do modelo foi possível verificar que existe sazonalidade entre os dias da semana, sendo que existe uma tendência do número médio de internações ser menor nos finais de semana e ser maior às segundasfeiras.

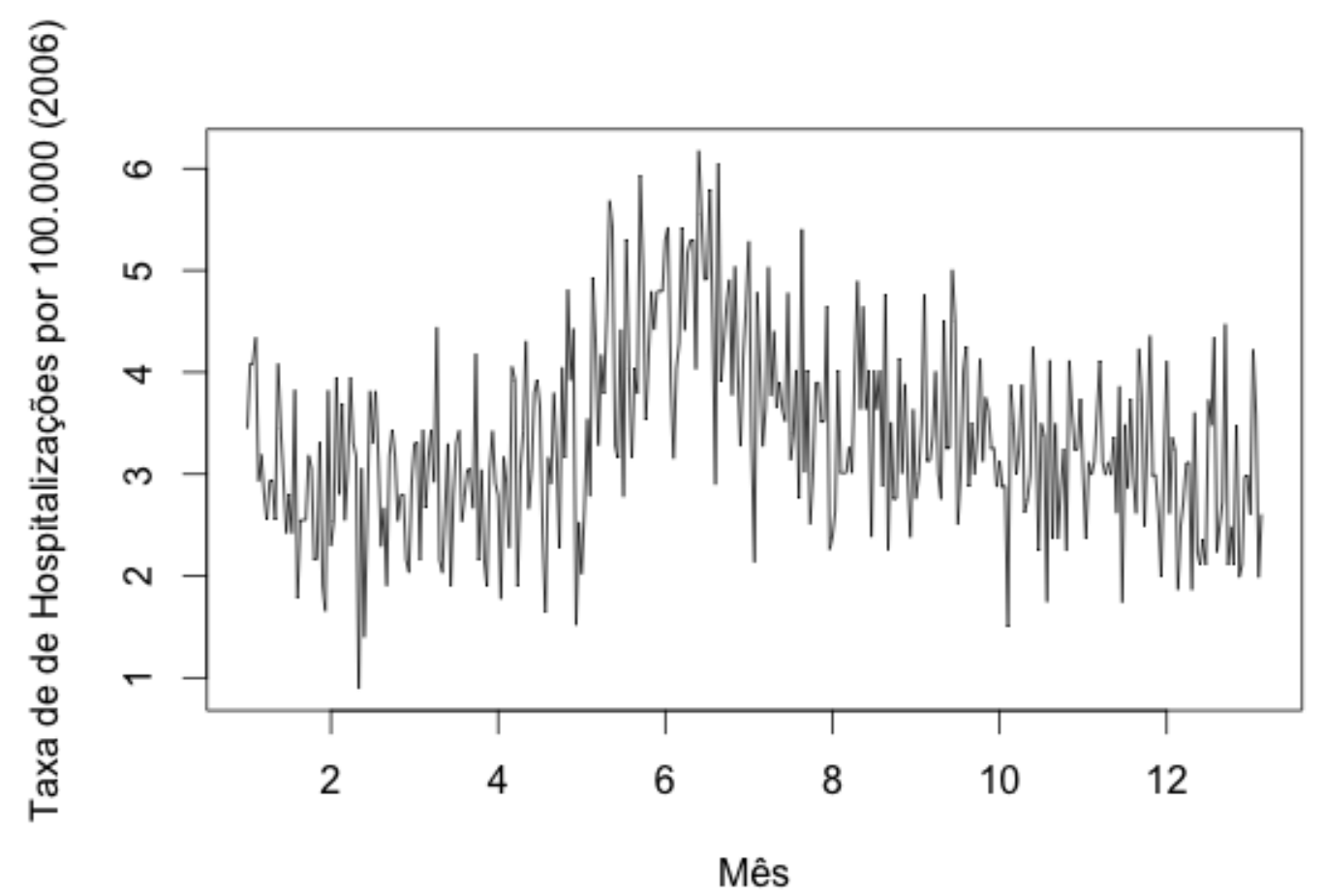

Figura 4: Internações diárias devido a doenças respiratórias para pessoas acimada de 65 anos na cidade de São Paulo em 2006

\subsection{Modelo}

Para modelar o comportamento da taxa de internações, foi utilizado um Modelo Linear Generalizado (MLG) com distribuição binomial negativa e o logaritmo como função de ligação. Neste ajuste, foram utilizados os dados do período de Janeiro de 2006 a Dezembro de 2010 e foram aplicados os gráficos de controle para os dados do ano de 2011.

O modelo utilizou como covariáveis o indicador do dia da semana (sábado, domingo, segunda), seno e cosseno com um período de um ano para descrever a sazonalidade e o tamanho da população como offset.

Considerando $X_{t}$ o número diário de hospitalizações no dia $t$ e $X_{t}$ seguindo uma distribuição Binomial Negativa com parâmetros $\left(\mu_{0, t}, \phi\right)$, o valor esperado da média $\mu_{0, t}$ 
é definido conforme a Equação (2.1):

$$
\ln \left(\frac{\mu_{0, t}}{\text { pop }_{t}} 100000\right)=\beta_{0}+\beta_{1} \cos \left(\frac{2 \pi t}{365}\right)+\beta_{2} \operatorname{sen}\left(\frac{2 \pi t}{365}\right)+\beta_{3} S_{a b}+\beta_{4} D_{o m_{t}}+\beta_{5} S_{e g}
$$

onde pop $_{t}$ é o valor da população em risco no t-ésimo dia; $S a b_{t}, \operatorname{Dom}_{t}$ e $S e g_{t}$ são variáveis indicadoras dummies iguais a 1 se o dia é respectivamente Sábado, Domingo ou Segunda e zero caso contrário. O termo de deslocamento $p o p_{t} / 100000$ permite modelar a taxa média diária de internações por 100.000 habitantes.

Para o ajuste do modelo, foi utilizada a função glm.nb (Negative Binomial Generalized Linear Model) do pacote MASS (VENABLES; RIPLEY, 2002) disponível no software R (R Core Team, 2015). As estimativas dos parâmetros serão apresentadas na seção 3.1 .

\subsection{Simulação de cenários}

Para a avaliação do desempenho dos gráficos de controle, foram utilizadas simulações de cenários conforme as etapas mostradas na Figura 5.

Inicialmente define-se qual tipo de gráfico, CUSUM ou EWMA (com limite assintótico ou com limite exato), e qual das transformações (RS, JK, GN, JG, DR, RY ou LR) apresentadas na Parte I serão utilizados. A etapa seguinte consiste em buscar parâmetros para os gráficos de controle com o objetivo de atingir $A R L_{0}$ próximo de 500. Para o gráfico CUSUM é necessário escolher os parâmetros $k$ e $h$ e para o gráfico EWMA é necessário escolher os parâmetros $\lambda$ e L. Uma vez definidos os parâmetros, são simuladas 10.000 replicações para o modelo probabilístico apresentado na Equação (2.1) sem alteração na média $(\delta=1)$.

Com os parâmetros escolhidos de $k$ e $h$ para os gráficos CUSUM e de $\lambda$ e $L$ para os gráficos EWMA, é verificado se o $A R L_{0}$ está próximo de 500 . Caso não esteja próximo, escolhem-se novos parâmetros e estas etapas são repetidas até se encontrar uma combinação que atinja este objetivo. Quando enfim são encontrados tais parâmetros, simulam-se cenários de mudança na média $(\delta>1)$ com 10.000 replicações para cada cenário. Foram testados diferentes valores de aumento do valor esperado de $\mu_{1}=\delta \mu_{0}$ $\operatorname{com} \delta=1.25,1.5,1.75$ e 2.0. Para cada um destes cenários calcula-se então o valor do $A R L_{1}$ atingido. Todo este processo foi repetido com o objetivo de encontrar parâmetros "ótimos" que minimizassem o $A R L_{1}$ para os gráficos CUSUM e EWMA para todas as estatísticas, mantendo $A R L_{0}$ próximo de 500.

O processo de simulação foi implementado no software R (R Core Team, 2015). Para sorteio dos valores dos dados de contagem, foi utilizada a função rnegbin (Simulate Negative Binomial Variates) presente no pacote MASS (VENABLES; RIPLEY, 2002). Os resultados serão apresentados na seção 3.2. 


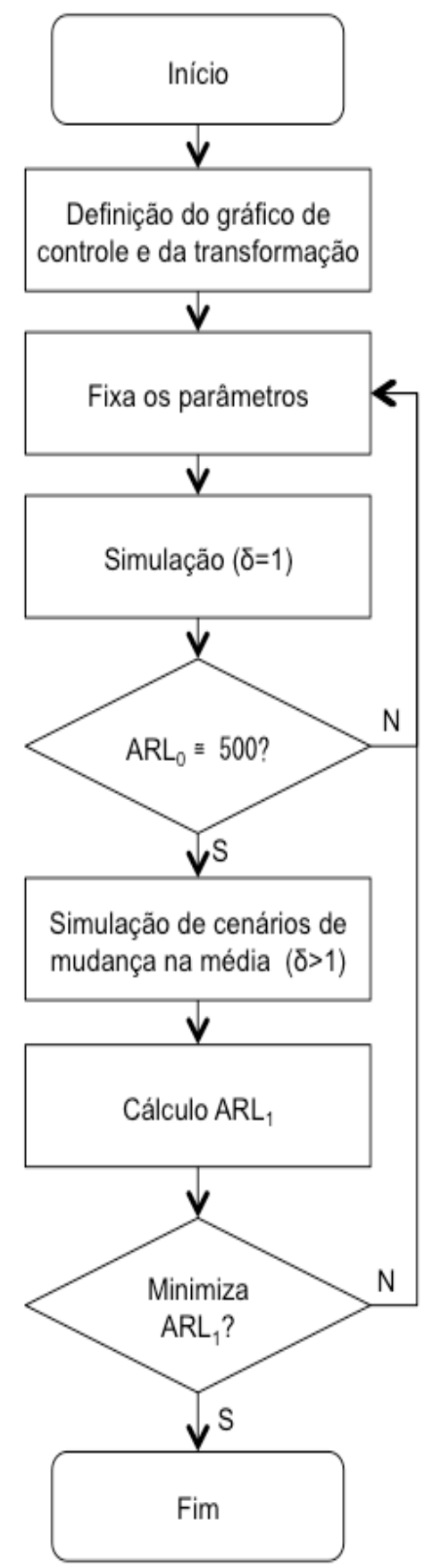

Figura 5: Etapas do processo de simulação 
Parte III

Resultados 



\section{Resultados}

Neste capítulo são apresentados os resultados obtidos neste projeto. Inicialmente são apresentadas as estimativas dos parâmetros conforme a Equação (2.1) para modelar o comportamento das internações devido a doenças respiratórias para pessoas acima de 65 anos. Em seguida, são mostrados os desempenhos obtidos em termos de $A R L_{1}$ pelos gráficos de controle para cada uma das transformações propostas.

\subsection{Ajuste do Modelo}

Usando os dados históricos do número de internações para pessoas acima de 65 anos entre Janeiro de 2006 a Dezembro de 2010, foi ajustado um modelo binomial negativo com uma função de ligação logarítmica conforme apresentado na Equação (2.1). As estimativas dos coeficientes $\beta_{i}$ são apresentadas na Tabela 1 .

Tabela 1: Estimativas, erros padrão e valores-p correspondentes aos parâmetros do modelo

\begin{tabular}{lccc}
\hline Coeficiente & Estimativa & Erro Padrãoo & Valor-p \\
\hline Intercepto $\left(\beta_{0}\right)$ & 1.227 & 0.007 & $<0.001$ \\
Cosseno $\left(\beta_{1}\right)$ & -0.173 & 0.007 & $<0.001$ \\
Seno $\left(\beta_{2}\right)$ & -0.045 & 0.007 & $<0.001$ \\
Sábado $\left(\beta_{3}\right)$ & -0.158 & 0.016 & $<0.001$ \\
Domingo $\left(\beta_{4}\right)$ & -0.207 & 0.016 & $<0.001$ \\
Segunda $\left(\beta_{5}\right)$ & 0.040 & 0.015 & 0.008 \\
\hline
\end{tabular}

Além destes parâmetros, a estimativa de dispersão $\phi$ foi igual a 66.99 com erro padrão de 8.22. Utilizando o pacote PSCL (JACKMAN, 2015) do software R, foi aplicado o teste de sobredispersão que compara o logaritmo do modelo com distribuição Binomial Negativa versus o logaritmo do modelo com distribuição de Poisson. Foi verificado que o valor-p do teste foi menor que $2.2 \mathrm{e}^{-16}$, ou seja, rejeita-se a hipótese nula de que a variância é igual a média (restrição do modelo com distribuição de Poisson), assim, indica-se a presença sobredispersão.

O ajuste do modelo proposto foi avaliado pela análise de resíduos. Como indicativa de um bom ajuste do modelo, o resíduo da desviância foi de 1847.7 com 1820 graus de liberdade. A Figura 6 apresenta o gráfico Quantil-Quantil para o resíduo da desviância e é possível verificar que ela está normalmente distribuída. Adicionalmente, o teste de Shapiro Wilks tem p-valor igual a 0.1997 , indicando que se aceita a premissa de normalidade.

Assumindo a premissa de que o período de ajuste do modelo foi não epidêmico, foi estimado o valor da média $\mu_{0}$ para o histórico de 2006 a 2010 usando as estimativas dos 


\section{Binomial Negativa}

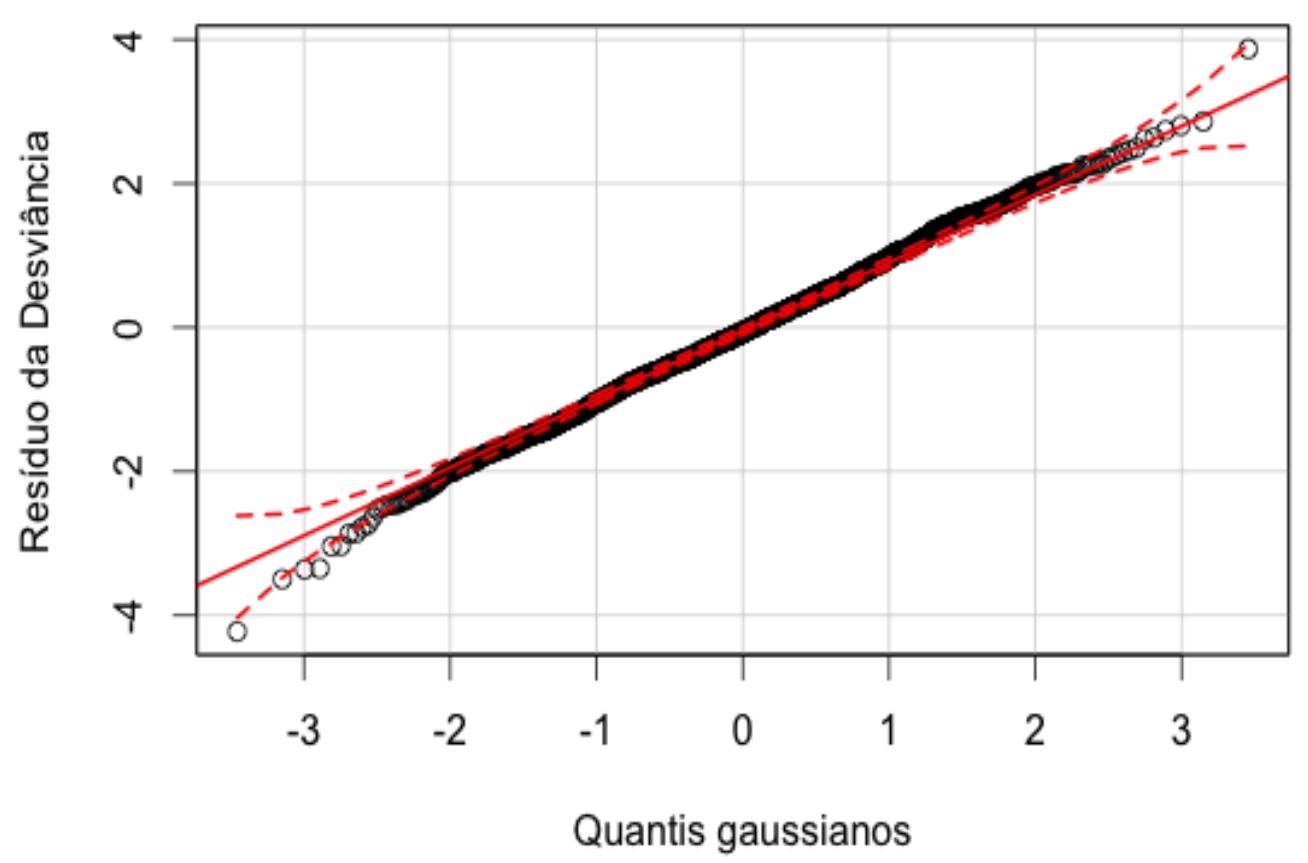

Figura 6: Gráfico Quantil-Quantil para Resíduo da Desviância

parâmetros da Tabela 1. A Figura 7 apresenta os valores ajustados da série para 2006 a 2010 (linha vermelha) e a média em controle $\mu_{0}$ para o número diário de hospitalizações em 2011 (linha azul). Como pode ser observado, o modelo consegue capturar o comportamento das internações para todo o período observado.

\subsection{Desempenho dos Gráficos de Controle}

Com base nas informações da Tabela 1 foram calculados os valores previstos para a média sob-controle $\mu_{0}$. São realizadas então 10.000 replicações para gerar valores futuros de hospitalizações de acordo com uma distribuição Binomial Negativa com média $\delta \mu_{0}$ e variância $\delta \mu_{0}+\left(\delta \mu_{0}\right)^{2} / \phi$.

Para cada par transformação/gráfico são procurados limites de controle e constantes que gerem valores $A R L_{0}$ próximo de 500. Uma vez encontrados estes parâmetros, são simulados cenários de aumento na média com $\mu_{1}=\delta \mu_{0}$. Para ser possível a comparação, neste trabalho optou-se por serem utilizados os valores avaliados por Alencar et al. (2015). Assim, $\delta=\{1 ; 1.25 ; 1.5 ; 1.75 ; 2\}$. Note que as transformações LR e RY expressas em (1.11) e (1.13) dependem da média fora de controle $\mu_{1}$. Nestes casos, estas foram calculadas para detectar mudanças para $\delta$ igual a 2 , mesmo nos cenários de simulação com diferentes valores de aumento na média. 


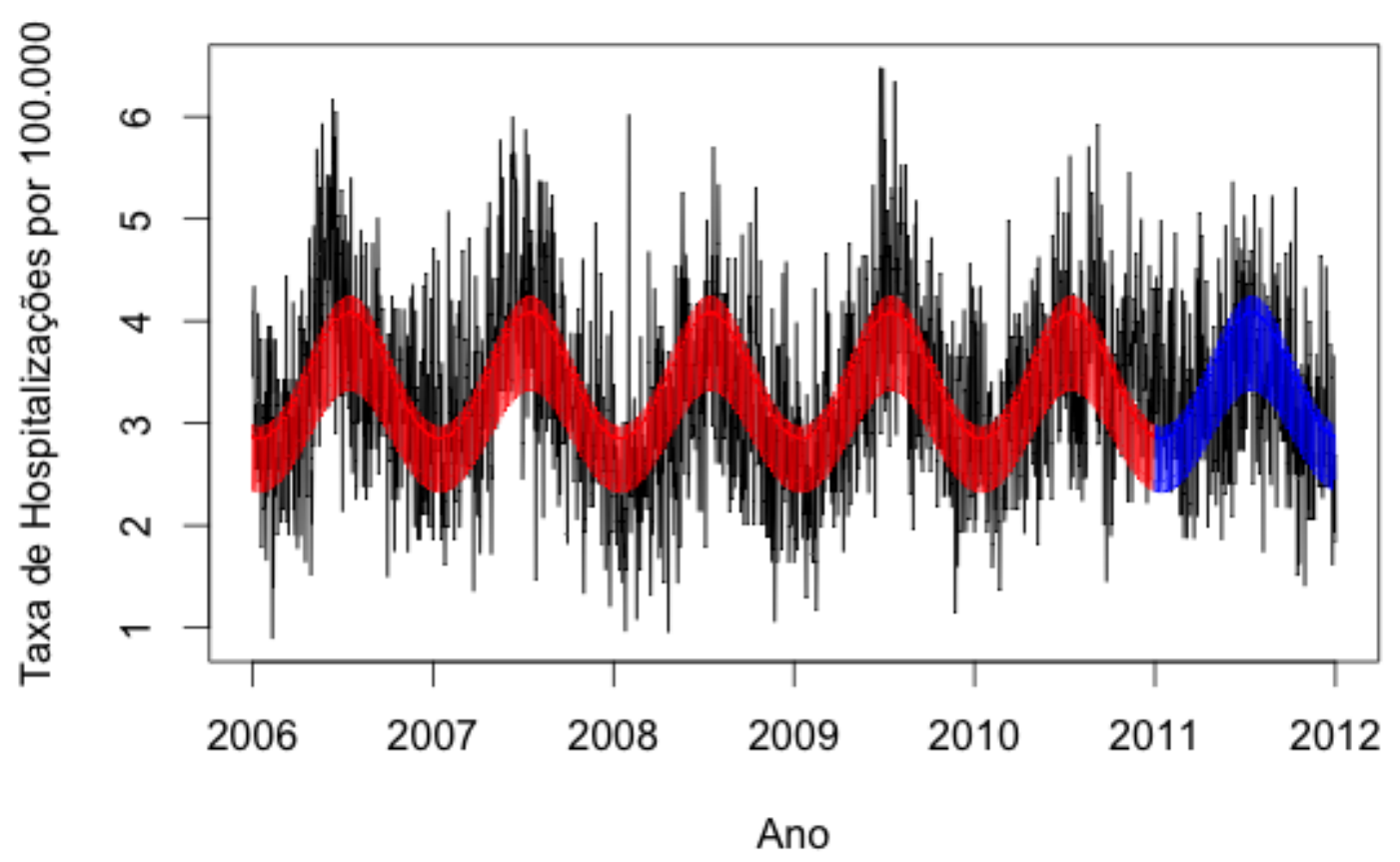

Figura 7: Internações diárias em São Paulo e valores ajustados

O desempenho dos gráficos é então avaliado pelo valores do $A R L_{1}$, sendo que valores menores são preferíveis, ou seja, uma alteração na média é detectada mais rapidamente.

Alencar et al. (2015) fizeram a busca por parâmetros "ótimos" de $k$ e $h$ dos gráficos CUSUM para os diversos cenários de mudança no número médio de internações. Os valores propostos pelos autores foram recalculados neste projeto e são apresentados na Tabela 2 . Para mostrar que sob $H_{0}$ todas as transformações possuem $A R L_{0}$ próximo de 500 , são apresentados os valores de $k$ e $h$ e os valores calculados do $A R L_{0}$. Além disso, Tabela 2 apresenta o desempenho de cada gráfico em termos de $A R L_{1}$.

Com exceção da transformação JK, foi possível encontrar valores de $A R L_{1}$ muito próximos ao trabalho anterior. Para a transformação JK, não foi possível encontrar os mesmos resultados, porém, as estimativas foram ajustadas de forma a alcançar $A R L_{0}$ próximo de 500 e minimizar o $A R L_{1}$ para cada $\delta>1$.

São confirmados os resultados apresentados no trabalho anterior. Para mudanças pequenas, as transformações RY e LR apresentam melhor desempenho com menores valores de $A R L_{1}$, levando uma semana para detecção de mudanças na média. Para $\delta$ maiores, a transformação LR apresenta o melhor desempenho, mas as outras transformações possuem $A R L_{1}$ muito próximo, sendo todos em média menores que 1.5 dia. 
Tabela 2: Parâmetros $k$ e $h$ para gráfico CUSUM

\begin{tabular}{|c|c|c|c|c|c|}
\hline$\delta$ & Transf & $\mathrm{k}$ & $\mathrm{h}$ & $A R L_{0}$ & $\overline{A R L_{1}}$ \\
\hline \multirow{7}{*}{1.25} & $\mathrm{RS}$ & 0.6 & 5.28 & 502.68 & 9.36 \\
\hline & JK & 0.2 & 2.25 & 511.04 & 8.81 \\
\hline & GN & 0.3 & 2.42 & 500.63 & 9.48 \\
\hline & $\mathrm{JG}$ & 0.5 & 4.74 & 497.37 & 8.74 \\
\hline & DR & 0.5 & 4.10 & 514.56 & 8.81 \\
\hline & $\mathrm{RY}$ & -8.5 & 26.4 & 495.07 & 7.14 \\
\hline & LR & -3.8 & 11.9 & 491.13 & 7.34 \\
\hline \multirow{7}{*}{1.5} & $\mathrm{RS}$ & 1.1 & 3.20 & 494.90 & 3.45 \\
\hline & JK & 0.5 & 1.00 & 501.55 & 3.29 \\
\hline & GN & 0.5 & 1.56 & 503.85 & 3.50 \\
\hline & $\mathrm{JG}$ & 0.9 & 2.97 & 499.06 & 3.22 \\
\hline & DR & 0.9 & 2.46 & 495.11 & 3.28 \\
\hline & $\mathrm{RY}$ & -5.1 & 15.64 & 485.06 & 3.10 \\
\hline & LR & -3.1 & 8.92 & 497.57 & 3.01 \\
\hline \multirow{7}{*}{1.75} & $\mathrm{RS}$ & 1.5 & 2.37 & 499.50 & 2.03 \\
\hline & JK & 0.6 & 0.82 & 500.22 & 1.90 \\
\hline & GN & 0.8 & 0.96 & 501.29 & 2.06 \\
\hline & $\mathrm{JG}$ & 1.2 & 2.30 & 494.49 & 1.90 \\
\hline & DR & 1.2 & 1.84 & 503.47 & 1.88 \\
\hline & $\mathrm{RY}$ & -3.7 & 13.3 & 500.62 & 1.88 \\
\hline & $\mathrm{LR}$ & -1.5 & 5.56 & 500.85 & 1.81 \\
\hline \multirow{7}{*}{2} & $\mathrm{RS}$ & 1.6 & 2.22 & 496.91 & 1.45 \\
\hline & JK & 1.0 & 0.34 & 510.86 & 1.38 \\
\hline & GN & 1.0 & 0.7 & 488.15 & 1.42 \\
\hline & $\mathrm{JG}$ & 1.2 & 2.3 & 502.87 & 1.39 \\
\hline & DR & 1.2 & 1.84 & 500.48 & 1.39 \\
\hline & $\mathrm{RY}$ & -3.7 & 13.3 & 494.59 & 1.39 \\
\hline & LR & -1.5 & 5.56 & 493.23 & 1.34 \\
\hline
\end{tabular}

Já a Tabela 3 apresenta os cenários de calibração para as transformações usando o gráfico de controle EWMA de limite de controle assintótico. Em todas as transformações foram utilizados valores de $\lambda=\{0.1 ; 0.2 ; 0.5 ; 0.8 ; 1\}$.

O objetivo foi entender o comportamento do gráfico EWMA em função da variação de $\lambda$. Com estes valores, foram calibrados os limites superiores de controle a fim de se obter $A R L_{0}$ próximo de 500 . Uma vez definidos os parâmetros do gráfico, foram então simulados cenários de mudanças na média com $\delta=\{1 ; 1.25 ; 1.5 ; 1.75 ; 2\}$ para ser possível a comparação com gráfico CUSUM. Observa-se que para todas as transformações foi utilizada a média $z_{t}$ esperada em $t_{0}$ igual a média amostral. Para RY e LR, a média amostral é dependente de $\mu_{1}$ e esta foi calculada considerando $\delta=2$.

A Tabela 3 destaca em negrito o $A R L_{1}$ do $\lambda$ que apresentou o menor valor para 
Tabela 3: $A R L_{1}$ para gráficos EWMA com limite assintótico (LSC independente de $t$ )

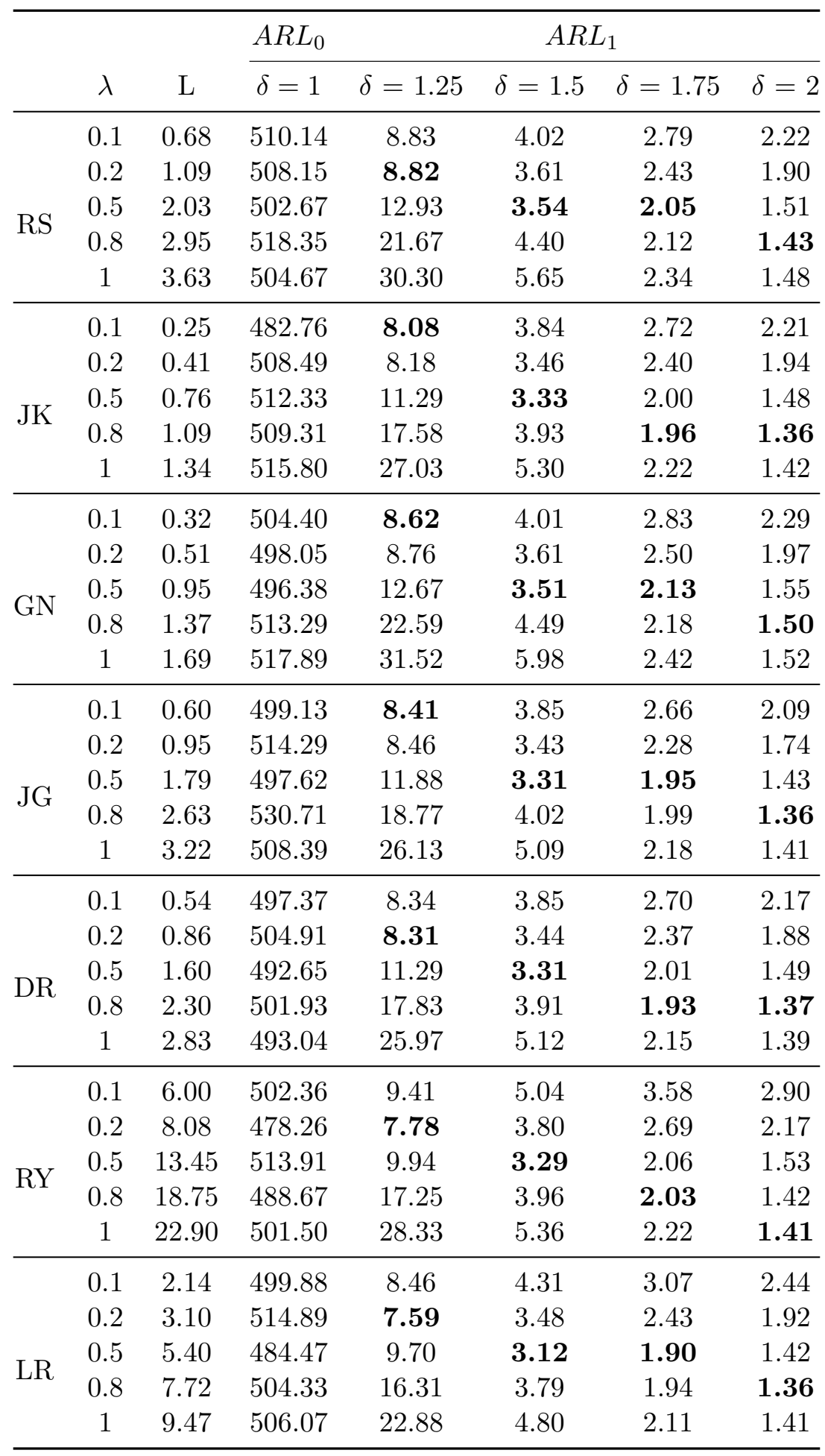


cada par transformação e $\delta$. Por exemplo, para a transformação RS com $\delta=1.25$, verificase que $\lambda=0.2$ tem $A R L_{1}=8.82$ que é o menor valor quando se compara com os outros valores de $A R L_{1}$ nesta mesma configuração.

Observando os resultados da Tabela 3 pode-se notar que, em geral, o gráfico EWMA comportou-se como esperado pela literatura. Para desvios pequenos, quanto menor o valor de $\lambda$ mais rápida é a deteç̧ão. Com $\delta=1.25, \lambda=0.1$ para as transformações JK, GN e JG e $\lambda=0.2$ para as transformações RS, DR, RY e LR tiveram valores menores de $A R L_{1}$. Quanto menor o valor de $\lambda$, maior o peso que as observações históricas na variável monitorada. Assim, quanto menor o desvio, mais importante fica a informação histórica, fazendo com que valores menores de $\lambda$ tenham melhor desempenho. Ainda para desvios pequenos, observa-se que o desempenho de valores maiores de $\lambda$ não é satisfatório, tendo casos em que se demora até 30 dias para detectar mudanças na média.

Para $\delta=1.5$ interessante observar que o valor de $\lambda=0.5$ apresentou o melhor desempenho em termos de $A R L_{1}$. Ou seja, o peso de uma nova observação é tão importante quanto a informação carregada do passado. Já para $\delta=1.75, \lambda=0.5$ para as transformações RS, GN, JG e LR e $\lambda=0.8$ para as transformações JK, DR e RY apresentaram menores valores de $A R L_{1}$.

Finalmente, para $\delta=2, \lambda=0.8$ apresentou o melhor desempenho para todas as transformação, exceto para a transformação RS que teve melhor desempenho para $\lambda=1$. Com desvios maiores, verifica-se que o peso de uma nova observação é mais importante que as observações históricas. Porém, observa-se que o desempenho para valores de $\lambda=$ 0.2 pode ser considerado satisfatório. A diferença do $A R L_{1}$ para $\lambda=0.8$ e $\lambda=0.2$ é aproximadamente 0.5 dias. Para efeito de comparação, com $\delta=1.25, \lambda=0.2$ detecta mudanças em média 10 dias mais rápido que $\lambda=0.8$.

Dentre todas as transformações, verifica-se que a LR apresentou o melhor desempenho para os valores de $\lambda$ que minimizam o $A R L_{1}$. Analisando as outras transformações, verifica-se que para desvios de $\delta$ iguais a 1.25 e 1.5, a transformação RY apresentou melhor desempenho. Para $\delta=1.75$, a transformação DR teve o melhor desempenho. Já para $\lambda=2$, o desempenho foi muito similar, sendo que as transformações JK, JG e DR apresentam aproximadamente os mesmos valores de $A R L_{1}$.

Assim, para a utilização deste gráfico na prática, seria recomendado a utilização da transformação LR, que apresentou o melhor desempenho com relação às outras transformações. Também seria recomendado a utilização do $\lambda=0.2$, pois apresentou melhor desempenho para desvios menores na média e para desvios maiores apresenta resultado próximo aos menores valores de $A R L_{1}$.

Também foram calculados os valores de $A R L_{1}$ para o EWMA com limite de controle exato, ou seja, dependente de $t$. Os resultados são apresentados na Tabela 4. 
Tabela 4: $A R L_{1}$ para gráficos EWMA com limite de controle exato (LSC dependente de $t$ )

\begin{tabular}{|c|c|c|c|c|c|c|c|}
\hline & \multirow[b]{2}{*}{$\lambda$} & \multirow[b]{2}{*}{$\mathrm{L}$} & \multirow{2}{*}{$\frac{A R L_{0}}{\delta=1}$} & \multicolumn{4}{|c|}{$A R L_{1}$} \\
\hline & & & & $\delta=1.25$ & $\delta=1.5$ & $\delta=1.75$ & $\delta=2$ \\
\hline \multirow{5}{*}{ RS } & 0.1 & 0.68 & 498.32 & 6.67 & 2.45 & 1.54 & 1.19 \\
\hline & 0.2 & 1.09 & 503.42 & 7.83 & 2.78 & 1.70 & 1.28 \\
\hline & 0.5 & 2.03 & 502.07 & 12.61 & 3.32 & 1.85 & 1.35 \\
\hline & 0.8 & 2.95 & 518.35 & 21.67 & 4.40 & 2.12 & 1.43 \\
\hline & 1 & 3.63 & 504.67 & 30.30 & 5.65 & 2.34 & 1.48 \\
\hline \multirow{5}{*}{ JK } & 0.1 & 0.26 & 509.04 & 6.12 & 2.36 & 1.51 & 1.19 \\
\hline & 0.2 & 0.41 & 503.29 & 7.13 & 2.59 & 1.62 & 1.24 \\
\hline & 0.5 & 0.76 & 511.34 & 10.94 & 3.09 & 1.79 & 1.33 \\
\hline & 0.8 & 1.09 & 509.16 & 17.56 & 3.93 & 1.95 & 1.36 \\
\hline & 1 & 1.34 & 515.80 & 27.03 & 5.30 & 2.22 & 1.42 \\
\hline \multirow{5}{*}{ GN } & 0.1 & 0.32 & 512.88 & 6.62 & 2.51 & 1.57 & 1.24 \\
\hline & 0.2 & 0.51 & 493.60 & 7.75 & 2.75 & 1.71 & 1.29 \\
\hline & 0.5 & 0.95 & 495.87 & 12.45 & 3.30 & 1.93 & 1.39 \\
\hline & 0.8 & 1.37 & 513.29 & 22.44 & 4.38 & 2.11 & 1.45 \\
\hline & 1 & 1.69 & 517.89 & 31.52 & 5.98 & 2.42 & 1.52 \\
\hline \multirow{5}{*}{ JG } & 0.1 & 0.60 & 500.14 & 6.31 & 2.39 & 1.51 & 1.20 \\
\hline & 0.2 & 0.95 & 509.04 & 7.43 & 2.60 & 1.61 & 1.24 \\
\hline & 0.5 & 1.79 & 496.42 & 11.52 & 3.07 & 1.75 & 1.29 \\
\hline & 0.8 & 2.63 & 530.71 & 18.77 & 4.02 & 1.99 & 1.36 \\
\hline & 1 & 3.22 & 508.39 & 26.13 & 5.09 & 2.18 & 1.41 \\
\hline \multirow{5}{*}{ DR } & 0.1 & 0.54 & 503.45 & 6.28 & 2.35 & 1.50 & 1.20 \\
\hline & 0.2 & 0.86 & 498.40 & 7.24 & 2.59 & 1.62 & 1.24 \\
\hline & 0.5 & 1.60 & 491.44 & 10.99 & 3.08 & 1.82 & 1.33 \\
\hline & 0.8 & 2.30 & 501.93 & 17.83 & 3.91 & 1.93 & 1.37 \\
\hline & 1 & 2.83 & 493.04 & 25.97 & 5.12 & 2.15 & 1.39 \\
\hline \multirow{5}{*}{ RY } & 0.1 & 6.00 & 492.79 & 7.54 & 3.30 & 2.08 & 1.55 \\
\hline & 0.2 & 8.08 & 472.52 & 6.92 & 2.98 & 1.89 & 1.43 \\
\hline & 0.5 & 13.45 & 513.27 & 9.70 & 3.06 & 1.86 & 1.37 \\
\hline & 0.8 & 18.75 & 488.31 & 17.06 & 3.86 & 1.96 & 1.36 \\
\hline & 1 & 22.90 & 501.50 & 28.33 & 5.36 & 2.22 & 1.41 \\
\hline \multirow{5}{*}{ LR } & 0.1 & 2.14 & 487.30 & 6.36 & 2.64 & 1.68 & 1.27 \\
\hline & 0.2 & 3.10 & 508.81 & 6.64 & 2.62 & 1.69 & 1.28 \\
\hline & 0.5 & 5.40 & 483.35 & 9.40 & 2.88 & 1.71 & 1.28 \\
\hline & 0.8 & 7.72 & 503.79 & 16.14 & 3.66 & 1.86 & 1.31 \\
\hline & 1 & 9.47 & 506.07 & 22.88 & 4.80 & 2.11 & 1.41 \\
\hline
\end{tabular}


Neste caso, observa-se um comportamento diferente em relação ao gráfico EWMA com limite assintótico. Em geral, tanto para desvios menores quanto para desvios maiores, quanto menor $\lambda$, menor o valor do $A R L_{1}$. Exceção ocorre para a transformação RY que teve menores valores para $\lambda=0.2 \operatorname{com} \delta$ igual a $1.25,1.5$, para $\lambda=0.5$ e $\delta=1.75$ e para $\lambda=0.8$ e $\delta=2$. Também para a transformação LR, o menor $A R L_{1}$ para $\delta=1.5$ foi com $\lambda=0.2$.

Além disso, ao contrário do gráfico anterior, onde a transformação LR apresentou o melhor desempenho independente da mudança na média, neste gráfico a transformação com o melhor desempenho depende do desvio. Para $\delta=1.25$ a transformação JK possui o menor valor de $A R L_{1}$. Para $\delta$ igual a 1.5 e 1.75 , a transformação DR teve o melhor desempenho. Já para $\delta=2$, as transformações RS e JK tiveram o melhor desempenho. Entretanto, ressalva-se que, a diferença entre as transformações neste caso é relativamente pequena, sendo para desvios pequenos a diferença entre o $A R L_{1}$ com melhor desempenho com o $A R L_{1}$ de pior desempenho é de apenas 0.8 dias e para desvios grandes $(\delta=2)$ a diferença é de apenas 0.24 dias.

Já a Tabela 5 apresenta uma comparação do desempenho do gráficos EWMA. É mostrada a diferença entre os valores do $A R L_{1}$ do gráfico com limite de controle assintótico menos o $A R L_{1}$ do gráfico com limite de controle exato.

É esperado que, em geral, o EWMA com limite de controle exato apresente valores menores de $A R L_{1}$, sendo que, quanto menor o valor de $\lambda$ maior a diferença. Além disso, para $\lambda=1$, o termo de detecção rápida fica igual zero, ou seja, LSC é independente de $t$ e, assim, não há diferença no $A R L_{1}$.

A Tabela 6 apresenta as comparações entre os gráficos CUSUM e EWMA para mudanças na média com $\delta=\{1.25 ; 1.5 ; 1.75 ; 2\}$. São apresentados os valores de $A R L_{1}$ com os parâmetros sugeridos por Alencar et al. (2015) para o gráfico CUSUM e os valores encontrados para os gráficos EWMA com LSC assintótico. Nesta tabela, para o par transformação e $\delta$, é destacado em negrito qual gráfico teve o melhor desempenho, ou seja, menor $A R L_{1}$. Por exemplo, para $\delta=1.25$ e transformação RS, o gráfico com melhor desempenho foi o EWMA com $\lambda=0.2$. Já para a transformação RY com mesmo $\delta$, o melhor gráfico foi o CUSUM, com menor $A R L_{1}$.

Verifica-se que, em geral, os valores de $A R L_{1}$ do gráfico CUSUM são próximos aos valores do gráfico EWMA com melhor desempenho. Para desvios pequenos $(\delta=1.25)$, o gráfico EWMA teve menor $A R L_{1}$ em relação ao gráfico CUSUM para a maioria das transformações, com exceção das transformações RY e LR. Já para valores de desvios intermediários com $\delta$ igual a 1.5 e 1.75, o gráfico CUSUM apresentou melhor desempenho para todas as transformações. Com desvios maiores $(\delta=2)$, os desempenhos entre os dois gráficos foram bem próximos, com uma diferença máxima de 0.8 dias. As transformações RS, JK, JG e DR tiveram desempenho ligeiramente melhor para o gráfico EWMA com 
Tabela 5: Comparação EWMA - $A R L_{1}$ do LSC exato menos $A L R_{1}$ do LSC assintótico

\begin{tabular}{|c|c|c|c|c|c|}
\hline & \multirow[b]{2}{*}{$\lambda$} & \multicolumn{4}{|c|}{ Diferença $A R L_{1}$} \\
\hline & & $\delta=1.25$ & $\delta=1.5$ & $\delta=1.75$ & $\delta=2$ \\
\hline \multirow{5}{*}{$\mathrm{RS}$} & 0.1 & 2.16 & 1.56 & 1.26 & 1.03 \\
\hline & 0.2 & 0.99 & 0.83 & 0.73 & 0.62 \\
\hline & 0.5 & 0.33 & 0.22 & 0.20 & 0.16 \\
\hline & 0.8 & 0.00 & 0.00 & 0.00 & 0.00 \\
\hline & 1 & 0.00 & 0.00 & 0.00 & 0.00 \\
\hline \multirow{5}{*}{ JK } & 0.1 & 1.97 & 1.47 & 1.20 & 1.02 \\
\hline & 0.2 & 1.05 & 0.87 & 0.79 & 0.70 \\
\hline & 0.5 & 0.34 & 0.24 & 0.21 & 0.15 \\
\hline & 0.8 & 0.02 & 0.01 & 0.00 & 0.00 \\
\hline & 1 & 0.00 & 0.00 & 0.00 & 0.00 \\
\hline \multirow{5}{*}{ GN } & 0.1 & 1.99 & 1.50 & 1.26 & 1.06 \\
\hline & 0.2 & 1.01 & 0.85 & 0.78 & 0.69 \\
\hline & 0.5 & 0.22 & 0.21 & 0.20 & 0.16 \\
\hline & 0.8 & 0.15 & 0.10 & 0.08 & 0.05 \\
\hline & 1 & 0.00 & 0.00 & 0.00 & 0.00 \\
\hline \multirow{5}{*}{ JG } & 0.1 & 2.10 & 1.47 & 1.15 & 0.89 \\
\hline & 0.2 & 1.03 & 0.83 & 0.67 & 0.50 \\
\hline & 0.5 & 0.36 & 0.24 & 0.20 & 0.14 \\
\hline & 0.8 & 0.00 & 0.00 & 0.00 & 0.00 \\
\hline & 1 & 0.00 & 0.00 & 0.00 & 0.00 \\
\hline \multirow{5}{*}{ DR } & 0.1 & 2.07 & 1.50 & 1.20 & 0.97 \\
\hline & 0.2 & 1.07 & 0.86 & 0.75 & 0.63 \\
\hline & 0.5 & 0.29 & 0.23 & 0.20 & 0.15 \\
\hline & 0.8 & 0.00 & 0.00 & 0.00 & 0.00 \\
\hline & 1 & 0.00 & 0.00 & 0.00 & 0.00 \\
\hline \multirow{5}{*}{ RY } & 0.1 & 1.87 & 1.73 & 1.50 & 1.35 \\
\hline & 0.2 & 0.86 & 0.82 & 0.80 & 0.73 \\
\hline & 0.5 & 0.24 & 0.22 & 0.20 & 0.15 \\
\hline & 0.8 & 0.19 & 0.10 & 0.08 & 0.05 \\
\hline & 1 & 0.00 & 0.00 & 0.00 & 0.00 \\
\hline \multirow{5}{*}{ LR } & 0.1 & 2.10 & 1.67 & 1.38 & 1.16 \\
\hline & 0.2 & 0.95 & 0.86 & 0.74 & 0.65 \\
\hline & 0.5 & 0.30 & 0.24 & 0.19 & 0.14 \\
\hline & 0.8 & 0.17 & 0.13 & 0.08 & 0.05 \\
\hline & 1 & 0.00 & 0.00 & 0.00 & 0.00 \\
\hline
\end{tabular}


Tabela 6: Comparativo de $A R L_{1}$ dos gráficos CUSUM e EWMA com limite assintótico

\begin{tabular}{|c|c|c|c|c|c|c|c|}
\hline \multirow{2}{*}{$\delta$} & \multirow{2}{*}{ Transf } & \multirow{2}{*}{ CUSUM } & \multicolumn{5}{|c|}{ EWMA } \\
\hline & & & $\lambda=0.1$ & $\lambda=0.2$ & $\lambda=0.5$ & $\lambda=0.8$ & $\lambda=1$ \\
\hline \multirow{7}{*}{1.25} & $\mathrm{RS}$ & 9.36 & 8.83 & 8.82 & 12.93 & 21.67 & 30.30 \\
\hline & JK & 8.81 & 8.08 & 8.18 & 11.29 & 17.58 & 27.03 \\
\hline & GN & 9.48 & 8.62 & 8.76 & 12.67 & 22.59 & 31.52 \\
\hline & $\mathrm{JG}$ & 8.74 & 8.41 & 8.46 & 11.88 & 18.77 & 26.13 \\
\hline & DR & 8.81 & 8.34 & 8.31 & 11.29 & 17.83 & 25.97 \\
\hline & RY & 7.14 & 9.41 & 7.78 & 9.94 & 17.25 & 28.33 \\
\hline & $\mathrm{LR}$ & 7.34 & 8.46 & 7.59 & 9.70 & 16.31 & 22.88 \\
\hline \multirow{7}{*}{1.5} & $\mathrm{RS}$ & 3.45 & 4.02 & 3.61 & 3.54 & 4.40 & 5.65 \\
\hline & JK & 3.29 & 3.84 & 3.46 & 3.33 & 3.93 & 5.30 \\
\hline & GN & 3.50 & 4.01 & 3.61 & 3.51 & 4.49 & 5.98 \\
\hline & JG & 3.22 & 3.85 & 3.43 & 3.31 & 4.02 & 5.09 \\
\hline & DR & 3.28 & 3.85 & 3.44 & 3.31 & 3.91 & 5.12 \\
\hline & $\mathrm{RY}$ & 3.10 & 5.04 & 3.80 & 3.29 & 3.96 & 5.36 \\
\hline & LR & 3.01 & 4.31 & 3.48 & 3.12 & 3.79 & 4.80 \\
\hline \multirow{7}{*}{1.75} & $\mathrm{RS}$ & 2.03 & 2.79 & 2.43 & 2.05 & 2.12 & 2.34 \\
\hline & JK & 1.90 & 2.72 & 2.40 & 2.00 & 1.96 & 2.22 \\
\hline & GN & 2.06 & 2.83 & 2.50 & 2.13 & 2.18 & 2.42 \\
\hline & JG & 1.90 & 2.66 & 2.28 & 1.95 & 1.99 & 2.18 \\
\hline & DR & 1.88 & 2.70 & 2.37 & 2.01 & 1.93 & 2.15 \\
\hline & RY & 1.88 & 3.58 & 2.69 & 2.06 & 2.03 & 2.22 \\
\hline & LR & 1.81 & 3.07 & 2.43 & 1.90 & 1.94 & 2.11 \\
\hline \multirow{7}{*}{2} & $\mathrm{RS}$ & 1.45 & 2.22 & 1.90 & 1.51 & 1.43 & 1.48 \\
\hline & JK & 1.38 & 2.21 & 1.94 & 1.48 & 1.36 & 1.42 \\
\hline & GN & 1.42 & 2.29 & 1.97 & 1.55 & 1.50 & 1.52 \\
\hline & $\mathrm{JG}$ & 1.39 & 2.09 & 1.74 & 1.43 & 1.36 & 1.41 \\
\hline & DR & 1.39 & 2.17 & 1.88 & 1.49 & 1.37 & 1.39 \\
\hline & $\mathrm{RY}$ & 1.39 & 2.90 & 2.17 & 1.53 & 1.42 & 1.41 \\
\hline & LR & 1.34 & 2.44 & 1.92 & 1.42 & 1.36 & 1.41 \\
\hline
\end{tabular}


$\lambda=0.8$ e as transformações GN, RY e LR foram ligeiramente melhores para o gráfico CUSUM.

Já a Tabela 7 apresenta as comparações entre os gráficos CUSUM e EWMA com LSC exato.

Tabela 7: Comparativo de $A R L_{1}$ dos gráficos CUSUM e EWMA com limite de controle exato

\begin{tabular}{|c|c|c|c|c|c|c|c|}
\hline \multirow{2}{*}{$\delta$} & \multirow{2}{*}{ Transf } & \multirow{2}{*}{ CUSUM } & \multicolumn{5}{|c|}{ EWMA } \\
\hline & & & $\lambda=0.1$ & $\lambda=0.2$ & $\lambda=0.5$ & $\lambda=0.8$ & $\lambda=1$ \\
\hline \multirow{7}{*}{1.25} & $\mathrm{RS}$ & 9.36 & 6.67 & 7.83 & 12.61 & 21.67 & 30.30 \\
\hline & JK & 8.81 & 6.12 & 7.13 & 10.94 & 17.56 & 27.03 \\
\hline & GN & 9.48 & 6.62 & 7.75 & 12.45 & 22.44 & 31.52 \\
\hline & $\mathrm{JG}$ & 8.74 & 6.31 & 7.43 & 11.52 & 18.77 & 26.13 \\
\hline & DR & 8.81 & 6.28 & 7.24 & 10.99 & 17.83 & 25.97 \\
\hline & $\mathrm{RY}$ & 7.14 & 7.54 & 6.92 & 9.70 & 17.06 & 28.33 \\
\hline & $\mathrm{LR}$ & 7.34 & 6.36 & 6.64 & 9.40 & 16.14 & 22.88 \\
\hline \multirow{7}{*}{1.5} & $\mathrm{RS}$ & 3.45 & 2.45 & 2.78 & 3.32 & 4.40 & 5.65 \\
\hline & JK & 3.29 & 2.36 & 2.59 & 3.09 & 3.93 & 5.30 \\
\hline & GN & 3.50 & 2.51 & 2.75 & 3.30 & 4.38 & 5.98 \\
\hline & $\mathrm{JG}$ & 3.22 & 2.39 & 2.60 & 3.07 & 4.02 & 5.09 \\
\hline & DR & 3.28 & 2.35 & 2.59 & 3.08 & 3.91 & 5.12 \\
\hline & $\mathrm{RY}$ & 3.10 & 3.30 & 2.98 & 3.06 & 3.86 & 5.36 \\
\hline & $\mathrm{LR}$ & 3.01 & 2.64 & 2.62 & 2.88 & 3.66 & 4.80 \\
\hline \multirow{7}{*}{1.75} & $\mathrm{RS}$ & 2.03 & 1.54 & 1.70 & 1.85 & 2.12 & 2.34 \\
\hline & JK & 1.90 & 1.51 & 1.62 & 1.79 & 1.95 & 2.22 \\
\hline & GN & 2.06 & 1.57 & 1.71 & 1.93 & 2.11 & 2.42 \\
\hline & $\mathrm{JG}$ & 1.90 & 1.51 & 1.61 & 1.75 & 1.99 & 2.18 \\
\hline & DR & 1.88 & 1.50 & 1.62 & 1.82 & 1.93 & 2.15 \\
\hline & $\mathrm{RY}$ & 1.88 & 2.08 & 1.89 & 1.86 & 1.96 & 2.22 \\
\hline & $\mathrm{LR}$ & 1.81 & 1.68 & 1.69 & 1.71 & 1.86 & 2.11 \\
\hline \multirow{7}{*}{2} & $\mathrm{RS}$ & 1.45 & 1.19 & 1.28 & 1.35 & 1.43 & 1.48 \\
\hline & JK & 1.38 & 1.19 & 1.24 & 1.33 & 1.36 & 1.42 \\
\hline & GN & 1.42 & 1.24 & 1.29 & 1.39 & 1.45 & 1.52 \\
\hline & $\mathrm{JG}$ & 1.39 & 1.20 & 1.24 & 1.29 & 1.36 & 1.41 \\
\hline & DR & 1.39 & 1.20 & 1.24 & 1.33 & 1.37 & 1.39 \\
\hline & $\mathrm{RY}$ & 1.39 & 1.55 & 1.43 & 1.37 & 1.36 & 1.41 \\
\hline & LR & 1.34 & 1.27 & 1.28 & 1.28 & 1.31 & 1.41 \\
\hline
\end{tabular}

Neste caso, observa-se que o gráfico EWMA teve melhor desempenho em relação ao gráfico CUSUM, principalmente, com valores de $\lambda$ iguais a 0.1 e 0.2 , mostrando, mais uma vez, o aumento no desempenho do gráfico EWMA ao se utilizar o termo de detecção 
rápida. 


\subsection{Aplicação dos Gráficos nos Dados Históricos}

Para ilustrar a aplicação do gráfico de controle por usuários na prática, os gráficos CUSUM e EWMA foram aplicados ao ano de 2011 usando as transformações apresentadas neste projeto. Foram utilizados os parâmetros calibrados para detectar aumento de $50 \%$ $(\delta=1.5)$ na média. Para o gráfico EWMA, foram utilizados os parâmetros para $\lambda=0.2$ que possuem bom desempenho tanto para mudanças pequenas como grandes. As Figuras 8, 9, 10, 11, 12, 13 e 14 apresentam os gráficos CUSUM e EWMA para cada transformação. Já a Figura 15 apresenta o percentual da taxa de internação de 2011 sobre a média dos cinco anos anteriores. Valores positivos indicam que houve um aumento na taxa e valores negativos indicam uma diminuição na taxa de internações.

De forma geral, os gráficos CUSUM indicam epidemias no início de Janeiro, sendo que as transformações JG e LR detectam epidemias no $41^{\circ}$ (10 de fevereiro) e $40^{\circ}$ (9 de fevereiro) dia, respectivamente. Estes resultados são consistentes, pois diversos dias de Janeiro apresentam taxa de hospitalizações maiores que 50\% em relação aos anos anteriores.

Já os gráficos EWMA indicam epidemias em Janeiro e começo de Fevereiro, mas também indicaram por volta do $90^{\circ}$ dia (31 de março). Este resultado também é consistente, pois por volta do final de Março e início de Abril, é possível perceber que em diversos dias há um aumento da taxa de internação em 2011 quando comparados com os anos anteriores.
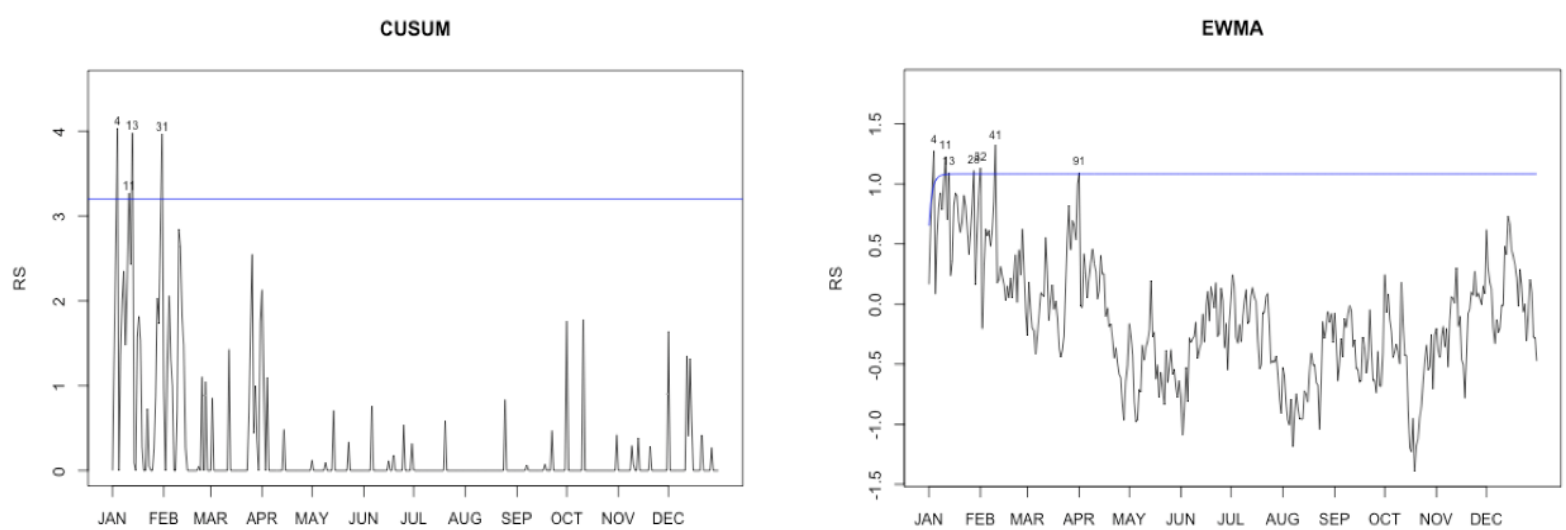

Figura 8: Gráficos de Controle CUSUM e EWMA no histórico com método RS 

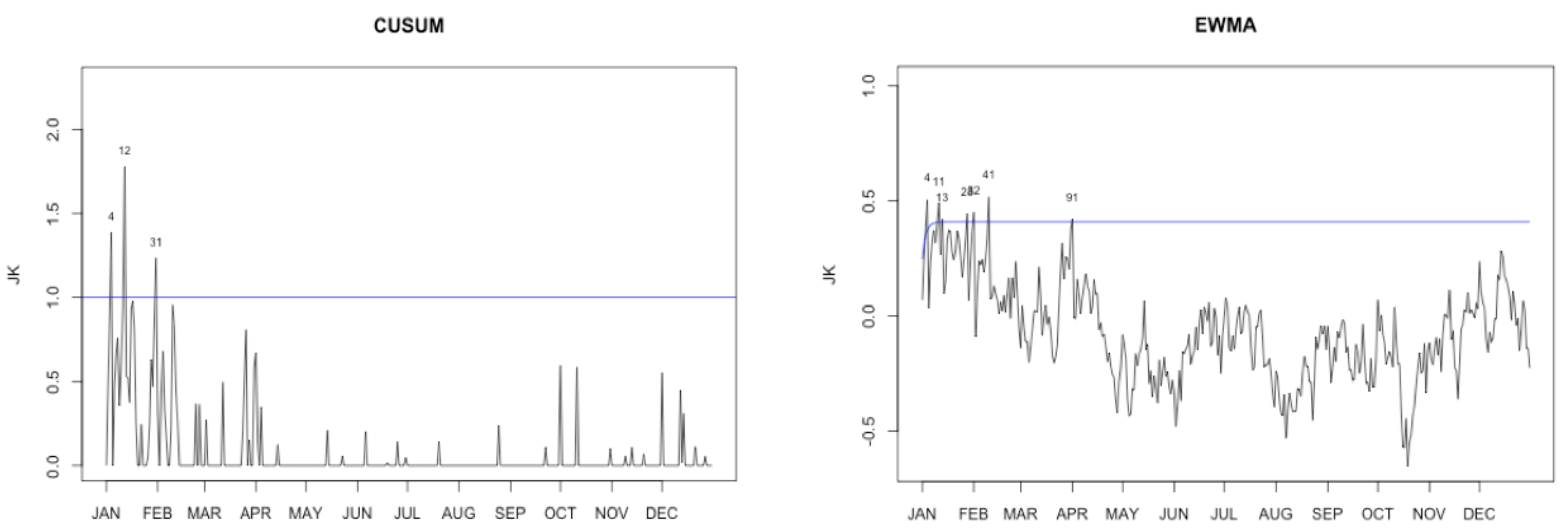

Figura 9: Gráficos de Controle CUSUM e EWMA no histórico com método JK
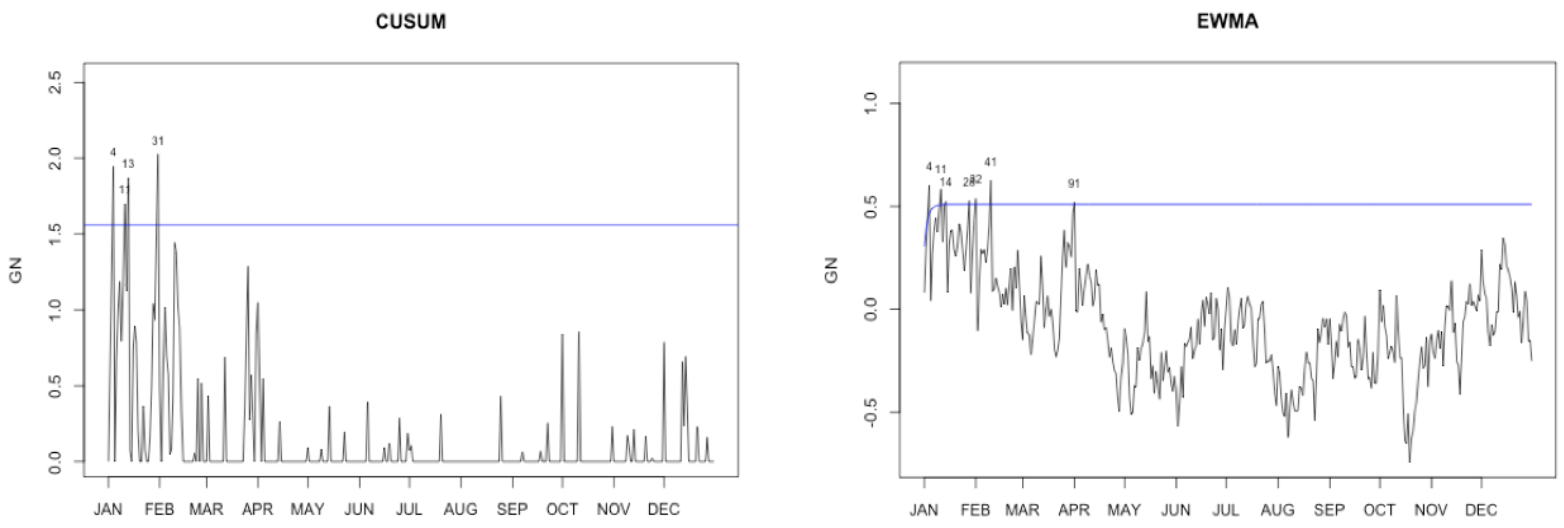

Figura 10: Gráficos de Controle CUSUM e EWMA no histórico com método GN
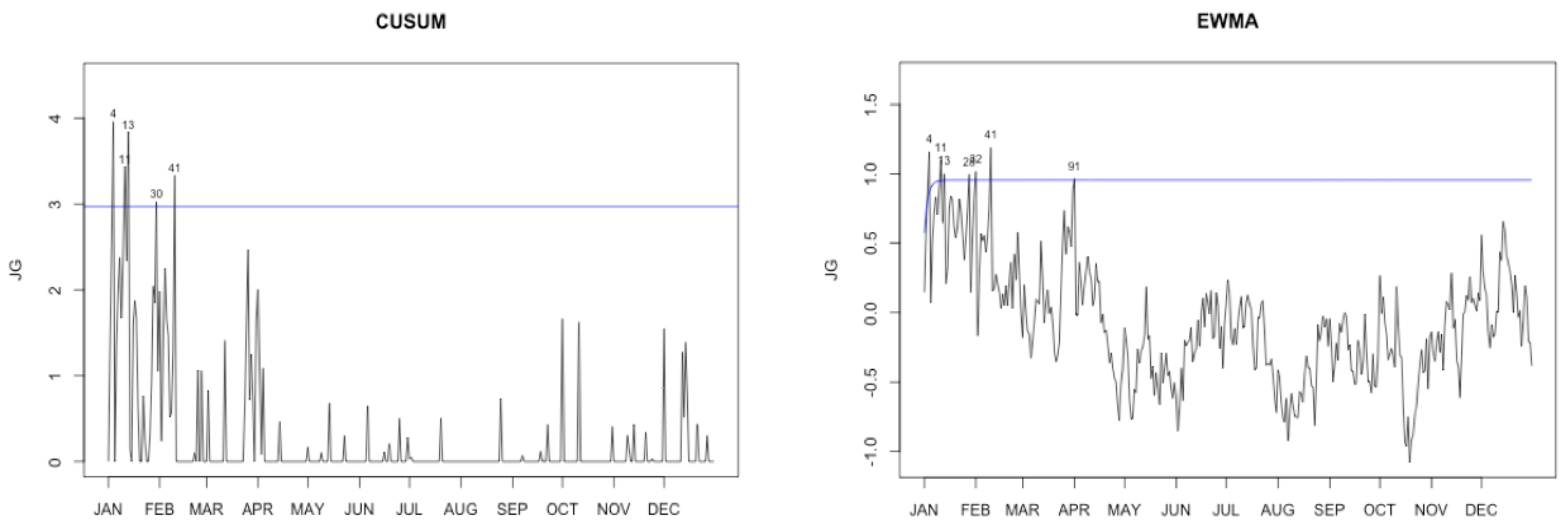

Figura 11: Gráficos de Controle CUSUM e EWMA no histórico com método JG 

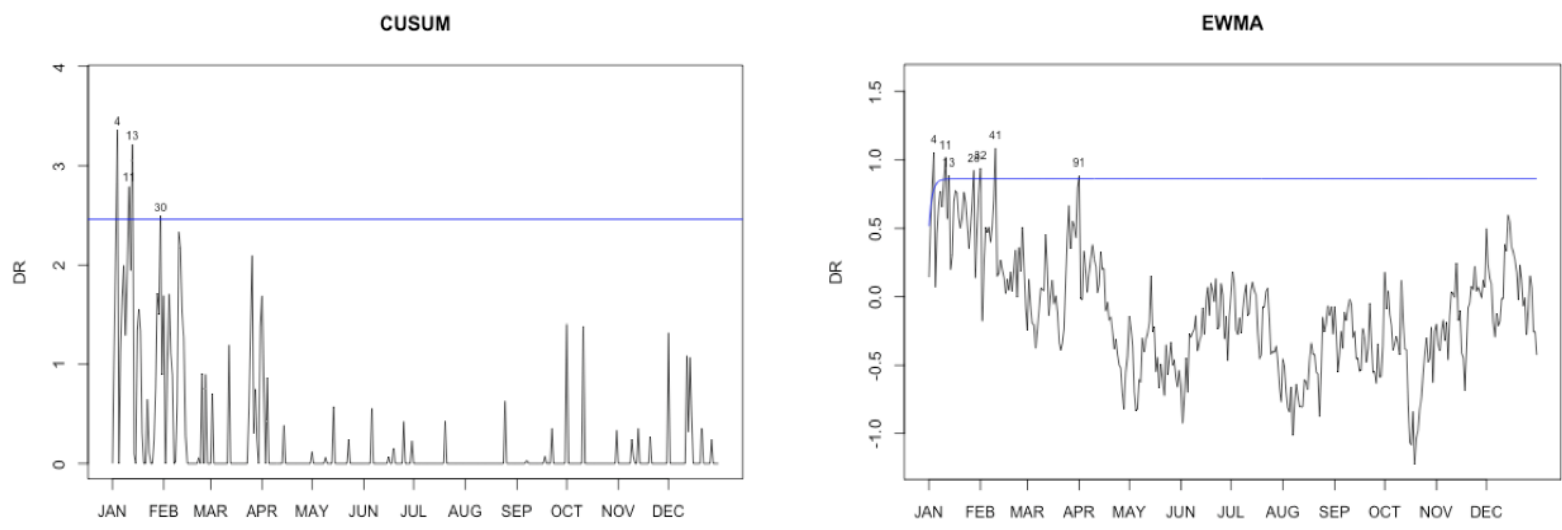

Figura 12: Gráficos de Controle CUSUM e EWMA no histórico com método DR
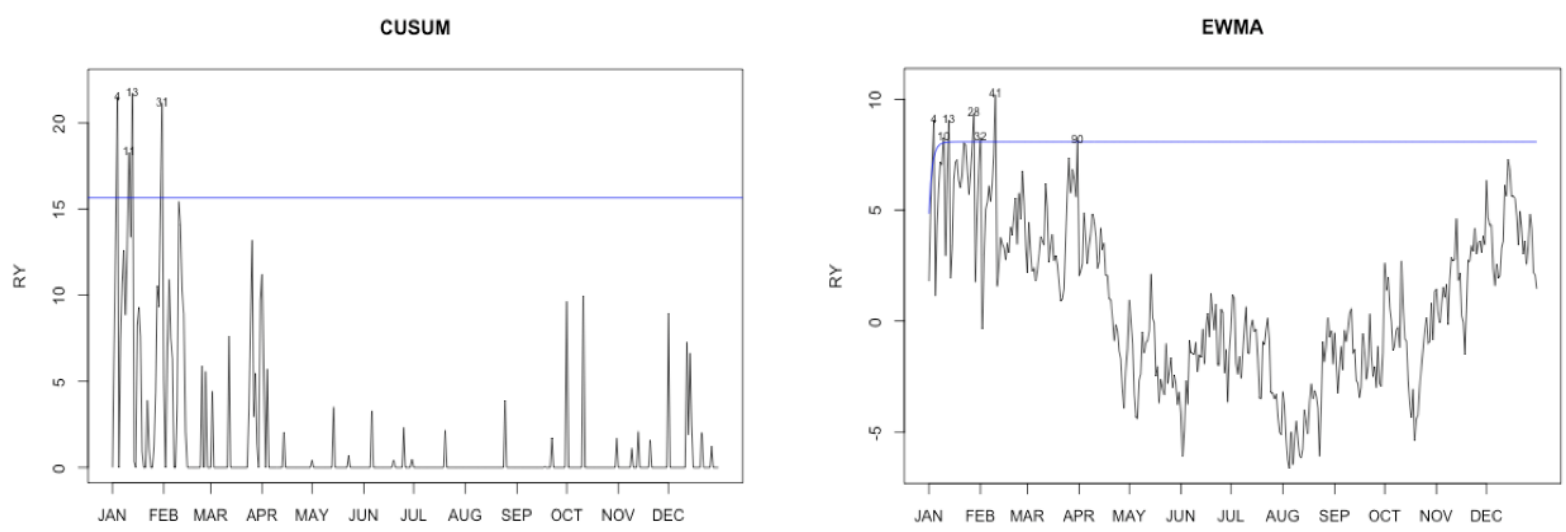

Figura 13: Gráficos de Controle CUSUM e EWMA no histórico com método RY
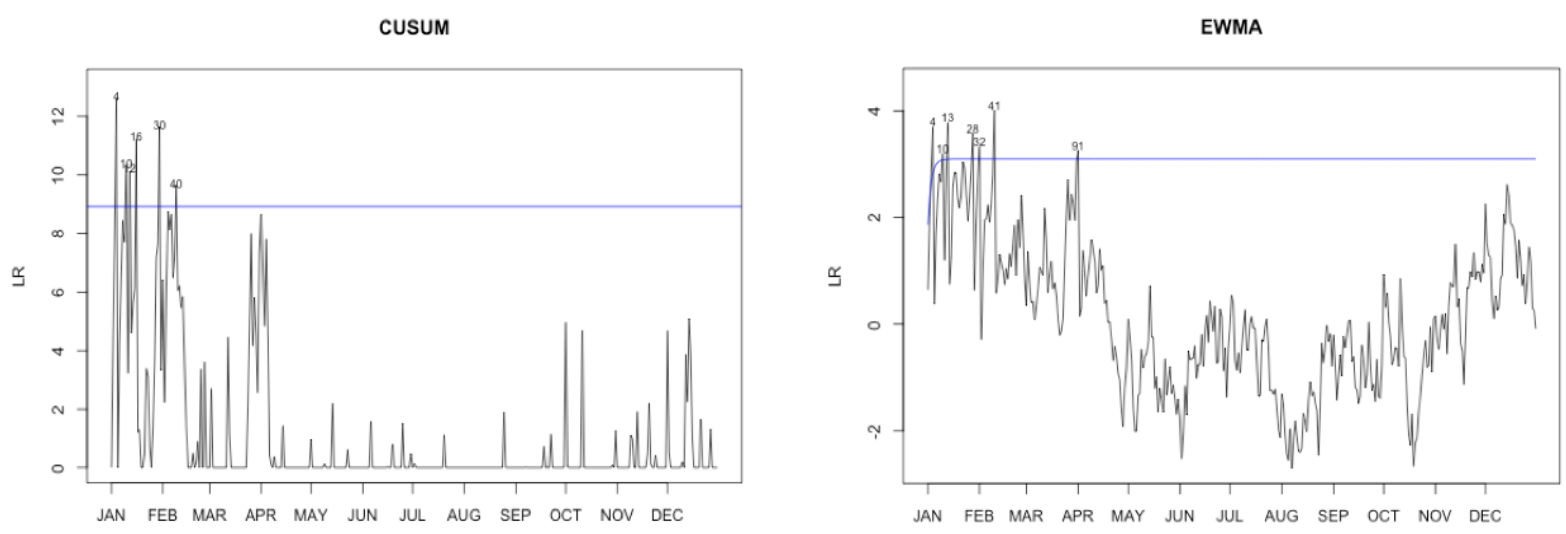

Figura 14: Gráficos de Controle CUSUM e EWMA no histórico com método LR 


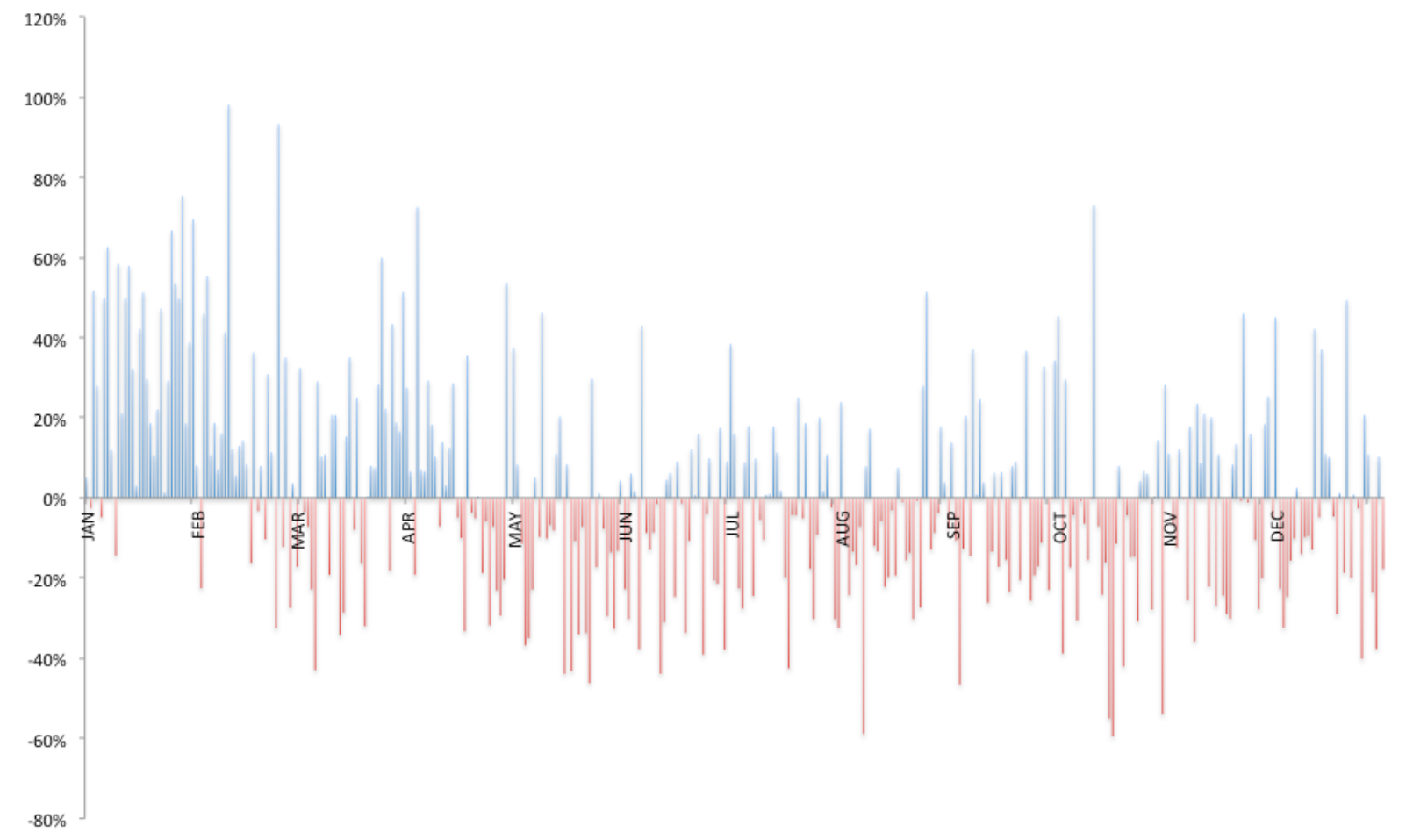

Figura 15: Comparação da taxa de internação de 2011 com anos anteriores 


\section{Conclusões}

Neste trabalho foi feita uma comparação do gráfico CUSUM com o gráfico EWMA para monitoramento do número diário de internações hospitalares. Para tanto, utilizando uma série histórica de internações devido a doenças respiratórias para a população acima de 65 anos na cidade de São Paulo, foi feito um ajuste de um modelo com distribuição Binomial Negativa empregando uma função de ligação logarítmica. Neste modelo foi utilizado o tamanho da população como baseline e também um conjunto de covariáveis.

Simulando diversos cenários de mudança no número médio de internações e utilizando diferentes estatísticas baseadas em transformações, foram recalculados os parâmetros para os gráficos CUSUM.

Além disso, foram implementados os gráficos EWMA com limite de controle assintótico e com limite de controle exato e estes foram aplicados com as mesmas transformações propostas no trabalho de Alencar et al. (2015).

Os gráficos foram comparados através da medida de desempenho $A R L_{1}$, que é o número médio de amostras necessárias até a sinalização que o processo está fora de controle.

Com relação ao gráfico CUSUM, foram encontrados resultados muito similares aos resultados de Alencar et al. (2015). Para $\delta$ s menores, as transformações RY e LR apresentam melhor desempenho com menores valores de $A R L_{1}$. Para $\delta$ s maiores, a transformação LR apresenta o melhor desempenho, mas as outras transformações possuem $A R L_{1}$ com valores próximos.

Com relação ao EWMA, é possível verificar que, em geral, o gráfico EWMA com limite de controle assintótico apresentou comportamento esperado na literatura. Para desvios pequenos quanto menor o valor de $\lambda$ mais rápida é a detecção. A transformação LR apresenta o melhor desempenho, porém, as outras transformações possuem resultados similares, sendo a diferença de no máximo um dia para $\delta$ s pequenos e menor que um dia para $\delta$ s grandes.

A utilização do gráfico EWMA com limite de controle exato melhora o desempenho do gráfico de controle para valores menores de $\lambda(<0.8)$.

Comparando os gráficos CUSUM e EWMA, verifica-se que o EWMA com limite assintótico possui desempenho similar ao gráfico CUSUM, porém, o primeiro possui a vantagem de ter seus parâmetros mais facilmente calibrados.

Para a utilização dos gráficos na prática, a recomendação seria utilizar o gráfico EWMA com limite de controle exato, pois mostrou ter melhor desempenho (menor $A R L_{1}$ ). 
A utilização de $\lambda$ igual a 0.1 e 0.2 tem bom desempenho independente do cenário de mudança na média. Por ser mais fácil de implementar e calibrar, caso o usuário opte pelo gráfico EWMA com limite assintótico, a utilização de $\lambda=0.2$ mostra-se com bom desempenho para desvios pequenos e com desempenho satisfatório para maiores desvios na média. Para esta configuração, a transformação LR é a mais recomendada por ter menor $A R L_{1}$. Porém, outras transformações também podem ser utilizadas na prática. Por exemplo, a transformação RS pode ser mais facilmente compreendida pelos gestores da saúde e leva apenas 1.23 dia a mais para detectar mudanças no número médio de internações para $\delta=1.25$ em relação à transformação LR. Com $\delta=2$, esta diferença cai para apenas 0.07 dias.

Como desdobramento deste trabalho, sugere-se a implementação de regras suplementares que poderia aumentar a rapidez na detecção de mudanças na média, tanto para o gráfico CUSUM como para o gráfico EWMA. 


\section{Referências}

ALENCAR, A. P.; HO, L. L.; ALBARRACIN, O. Y. E. Cusum control charts to monitor series of negative binomial count data. Statistical methods in medical research, SAGE Publications, p. 0962280215592427, 2015. Citado 9 vezes nas páginas 21, 28, 29, 31, 37, $44,45,50$ e 59 .

BASSEVILLE, M.; NIKIFOROV, I. V. et al. Detection of abrupt changes: theory and application. [S.l.]: Prentice Hall Englewood Cliffs, 1993. Citado na página 28.

BROOK, D.; EVANS, D. An approach to the probability distribution of cusum run length. Biometrika, Biometrika Trust, v. 59, n. 3, p. 539-549, 1972. Citado na página 27.

BUCKERIDGE, D. L. et al. Algorithms for rapid outbreak detection: a research synthesis. Journal of biomedical informatics, Elsevier, v. 38, n. 2, p. 99-113, 2005. Citado na página 28.

CASEY, B. M.; MCINTIRE, D. D.; LEVENO, K. J. The continuing value of the apgar score for the assessment of newborn infants. New England Journal of Medicine, Mass Medical Soc, v. 344, n. 7, p. 467-471, 2001. Citado na página 27.

COSTA, A. F. B.; EPPRECHT, E. K.; CARPINETTI, L. C. R. Controle estatístico de qualidade. [S.l.]: Atlas São Paulo, 2013. Citado na página 32.

FALTIN, F.; KENETT, R.; RUGGERI, F. Statistical Methods in Healthcare. [S.l.]: John Wiley \& Sons, 2012. Citado na página 27.

FRICKER JR., R. D. Some methodological issues in biosurveillance. Statistics in medicine, Wiley Online Library, v. 30, n. 5, p. 403-415, 2011. Citado na página 28.

FRICKER JR., R. D. Introduction to Statistical Methods for Biosurveillance: With an Emphasis on Syndromic Surveillance. [S.l.]: Cambridge University Press, 2013. Citado na página 28.

FRICKER JR., R. D.; ROLKA, H. Protecting against biological terrorism: statistical issues in electronic biosurveillance. Chance, Taylor \& Francis, v. 19, n. 4, p. 4-14, 2006. Citado na página 28.

GANDY, A. et al. Risk-adjusted monitoring of time to event. Biometrika, Biometrika Trust, v. 97, n. 2, p. 375-388, 2010. Citado na página 27.

GRIGG, O.; FAREWELL, V. An overview of risk-adjusted charts. Journal of the Royal Statistical Society: Series A (Statistics in Society), Wiley Online Library, v. 167, n. 3, p. 523-539, 2004. Citado na página 27.

HARDIN, J. W.; HILBE, J. M.; HILBE, J. Generalized linear models and extensions. [S.l.]: Stata Press, 2007. Citado 2 vezes nas páginas 29 e 30.

HAWKINS, D. M.; OLWELL, D. H. Cumulative sum charts and charting for quality improvement. [S.l.]: Springer Science \& Business Media, 2012. Citado na página 31. 
HÖHLE, M.; PAUL, M. Count data regression charts for the monitoring of surveillance time series. Computational Statistics \& Data Analysis, Elsevier, v. 52, n. 9, p. 4357-4368, 2008. Citado 2 vezes nas páginas 28 e 31.

JACKMAN, S. pscl: Classes and Methods for $R$ Developed in the Political Science Computational Laboratory, Stanford University. Stanford, California, 2015. R package version 1.4.9. Disponível em: <http://pscl.stanford.edu/>. Citado na página 43.

JOHNSON, N. L.; KEMP, A. W.; KOTZ, S. Univariate discrete distributions. [S.1.]: John Wiley \& Sons, 2005. Citado na página 29.

JORGENSEN, B. The theory of dispersion models. [S.1.]: CRC Press, 1997. Citado na página 30.

KMAN, N. E.; BACHMANN, D. J. Biosurveillance: a review and update. Advances in preventive medicine, Hindawi Publishing Corporation, v. 2012, 2012. Citado na página 28.

LAI, T. L. Sequential changepoint detection in quality control and dynamical systems. Journal of the Royal Statistical Society. Series B (Methodological), JSTOR, p. 613-658, 1995. Citado na página 28.

LAI, T. L.; SHAN, J. Z. Efficient recursive algorithms for detection of abrupt changes in signals and control systems. Automatic Control, IEEE Transactions on, IEEE, v. 44, n. 5, p. 952-966, 1999. Citado na página 28.

LOMBARDO, M. J. et al. A systems overview of the electronic surveillance system for the early notification of community-based epidemics (essence ii). Journal of urban health, Springer, v. 80, n. 1, p. i32-i42, 2003. Citado na página 28.

MCCUlLAGH, P.; NELDER, J. A. Generalized linear models. [S.l.]: CRC press, 1989. Citado na página 30.

MCCULLOCH, C. E.; NEUHAUS, J. M. Generalized linear mixed models. [S.l.]: Wiley Online Library, 2001. Citado na página 30.

MONTGOMERY, D. C. Introduction to statistical process control. [S.l.]: John Wily \& Sons, New York, NY, 2009. Citado 3 vezes nas páginas 21, 25 e 32.

NELSON, L. S. A control chart for parts-per-million nonconforming items. Journal of Quality Technology, AMER SOC QUALITY CONTROL-ASQC ASQC MEMBERSHIP MANAGER 611 E. WISCONSIN AVENUE, MILWAUKEE, WI 53202, v. 26, n. 3, p. 239-240, 1994. Citado na página 27.

PAULINO, C. et al. Glossário inglês-português de estatística. Sociedade Portuguesa de Estatística e Associação Brasileira de Estatística, 2011. Citado na página 30.

R Core Team. R: A Language and Environment for Statistical Computing. Vienna, Austria, 2015. Disponível em: <http://www.R-project.org/>. C Citado na página 39.

ROBERTS, S. Control chart tests based on geometric moving averages. Technometrics, Taylor \& Francis, v. 1, n. 3, p. 239-250, 1959. Citado na página 32. 
ROGERSON, P. A.; YAMADA, I. Approaches to syndromic surveillance when data consist of small regional counts. Morbidity and Mortality Weekly Report, JSTOR, p. 79-85, 2004. Citado 2 vezes nas páginas 28 e 31.

ROSSI, G. Approximate poisson cusum charts for the monitoring of time series with time-varying mean. In: 45th Scientific Meeting of the Italian Statistical Society. [S.1.: s.n.], 2010. Citado na página 28.

ROSSI, G.; LAMPUGNANI, L.; MARCHI, M. An approximate cusum procedure for surveillance of health events. Statistics in medicine, v. 18, n. 16, p. 2111-2122, 1999. Citado 2 vezes nas páginas 28 e 29.

SANTIAGO, E.; SMITH, J. Control charts based on the exponential distribution: adapting runs rules for the t chart. Quality Engineering, Taylor \& Francis, v. 25, n. 2, p. 85-96, 2013. Citado na página 27.

SHMUELI, G.; BURKOM, H. Statistical challenges facing early outbreak detection in biosurveillance. Technometrics, v. 52, n. 1, 2010. Citado na página 28.

SKInNER, K. R.; MONTGOMERY, D. C.; RUNGER, G. C. Process monitoring for multiple count data using generalized linear model-based control charts. International Journal of Production Research, Taylor \& Francis, v. 41, n. 6, p. 1167-1180, 2003. Citado na página 28.

STEINER, S. H. et al. Monitoring surgical performance using risk-adjusted cumulative sum charts. Biostatistics, Biometrika Trust, v. 1, n. 4, p. 441-452, 2000. Citado na página 27.

SZARKA, J. L.; WOODALL, W. H. A review and perspective on surveillance of bernoulli processes. Quality and Reliability Engineering International, Wiley Online Library, v. 27, n. 6, p. 735-752, 2011. Citado na página 27.

TENNANT, R. et al. Monitoring patients using control charts: a systematic review. International Journal for Quality in Health Care, ISQHC, v. 19, n. 4, p. 187-194, 2007. Citado na página 27.

THOR, J. et al. Application of statistical process control in healthcare improvement: systematic review. Quality and Safety in Health Care, BMJ Publishing Group Ltd, v. 16, n. 5, p. 387-399, 2007. Citado na página 27.

UNKEL, S. et al. Statistical methods for the prospective detection of infectious disease outbreaks: a review. Journal of the Royal Statistical Society: Series A (Statistics in Society), Wiley Online Library, v. 175, n. 1, p. 49-82, 2012. Citado na página 27.

VENABLES, W. N.; RIPLEY, B. D. Modern Applied Statistics with S. Fourth. New York: Springer, 2002. ISBN 0-387-95457-0. Disponível em: <http://www.stats.ox.ac.uk/pub/MASS4>. Citado na página 39.

WINKEL, P.; ZHANG, N. F. Statistical development of quality in medicine. [S.l.]: John Wiley \& Sons, 2007. Citado na página 27.

WOODALL, W. H. Controversies and contradictions in statistical process control. Journal of Quality Technology, ASQC AMERICAN SOCIETY FOR QUALITY CONTROL, v. 32, n. 4, p. 341-350, 2000. Citado 2 vezes nas páginas 21 e 26. 
WOODALL, W. H. The use of control charts in health-care and public-health surveillance. Journal of Quality Technology, [Milwaukee]: American Society for Quality Control., v. 38, n. 2, p. 89-104, 2006. Citado 2 vezes nas páginas 21 e 27.

WOODALL, W. H. et al. On the use and evaluation of prospective scan methods for health-related surveillance. Journal of the Royal Statistical Society: Series A (Statistics in Society), Wiley Online Library, v. 171, n. 1, p. 223-237, 2008. Citado na página 27.

WOODALL, W. H.; MONTGOMERY, D. C. Some current directions in the theory and application of statistical process monitoring. Journal of Quality Technology, American Society for Quality, v. 46, n. 1, p. 78-94, 2014. Citado 2 vezes nas páginas 27 e 28.

YU, G. Variance stabilizing transformations of poisson, binomial and negative binomial distributions. Statistics \& Probability Letters, Elsevier, v. 79, n. 14, p. 1621-1629, 2009. Citado na página 30. 
Anexos 

ANEXO A - Programa R 
Segue abaixo o código desenvolvido na linguagem $\mathrm{R}$ para a análise deste projeto.

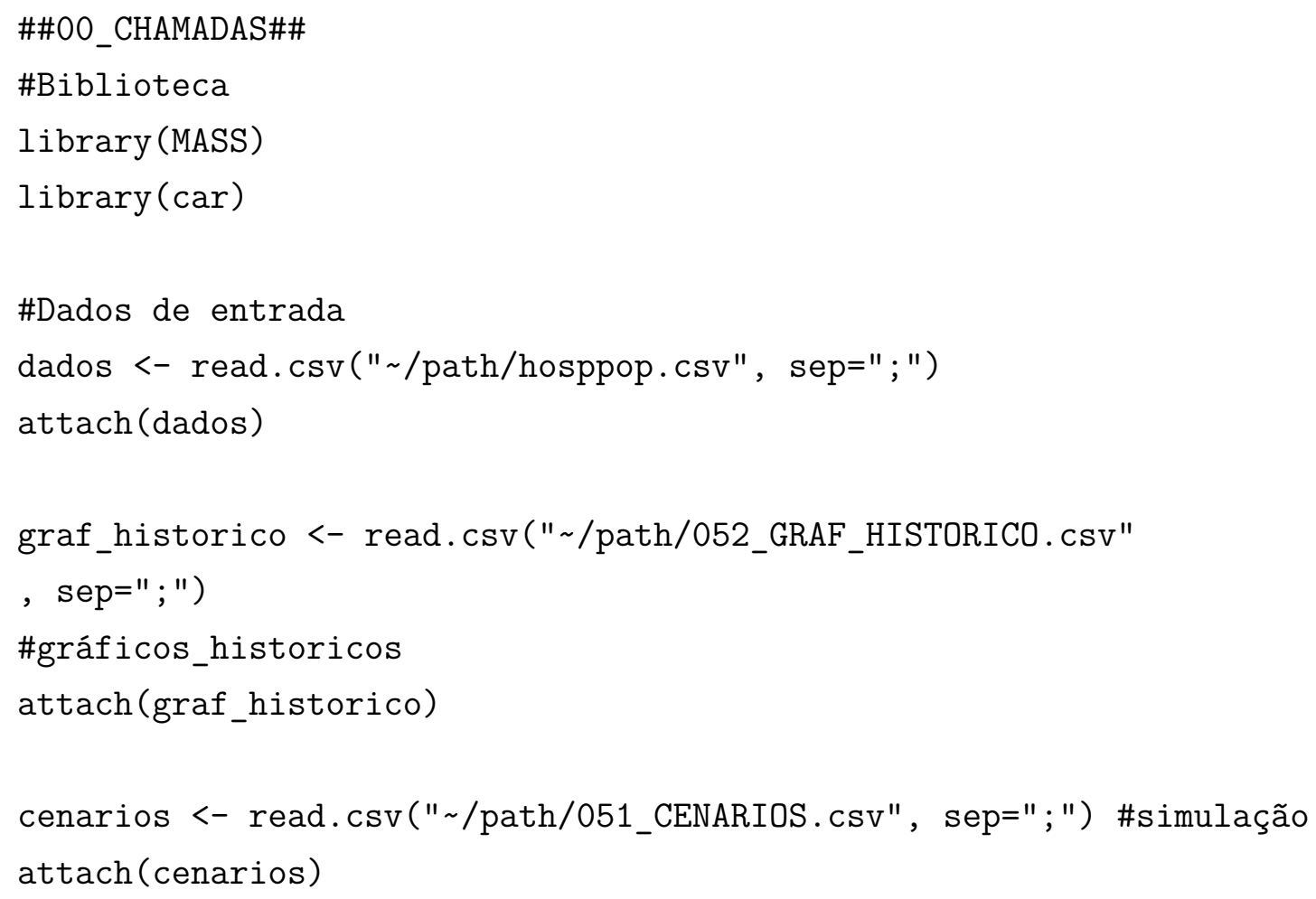




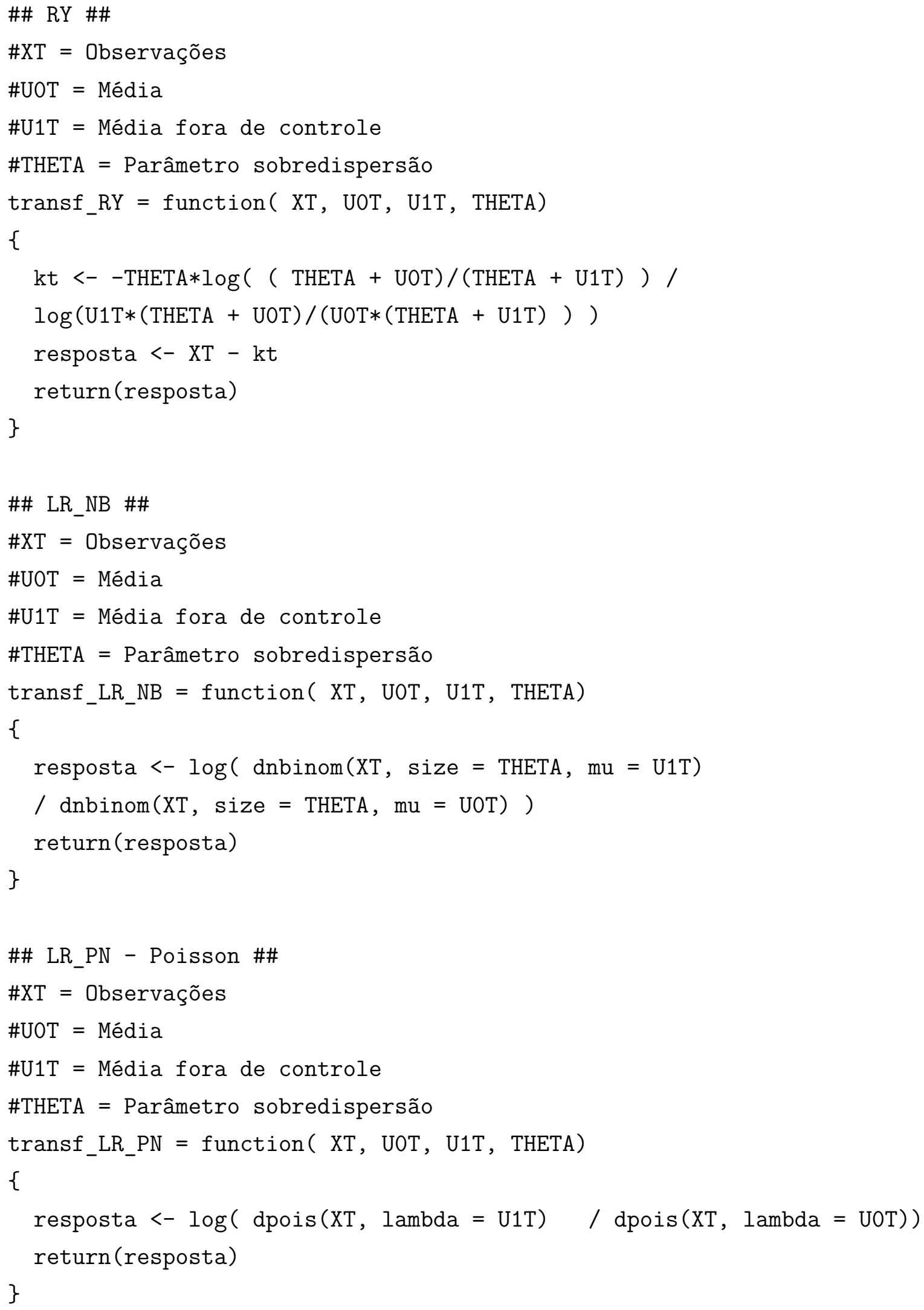




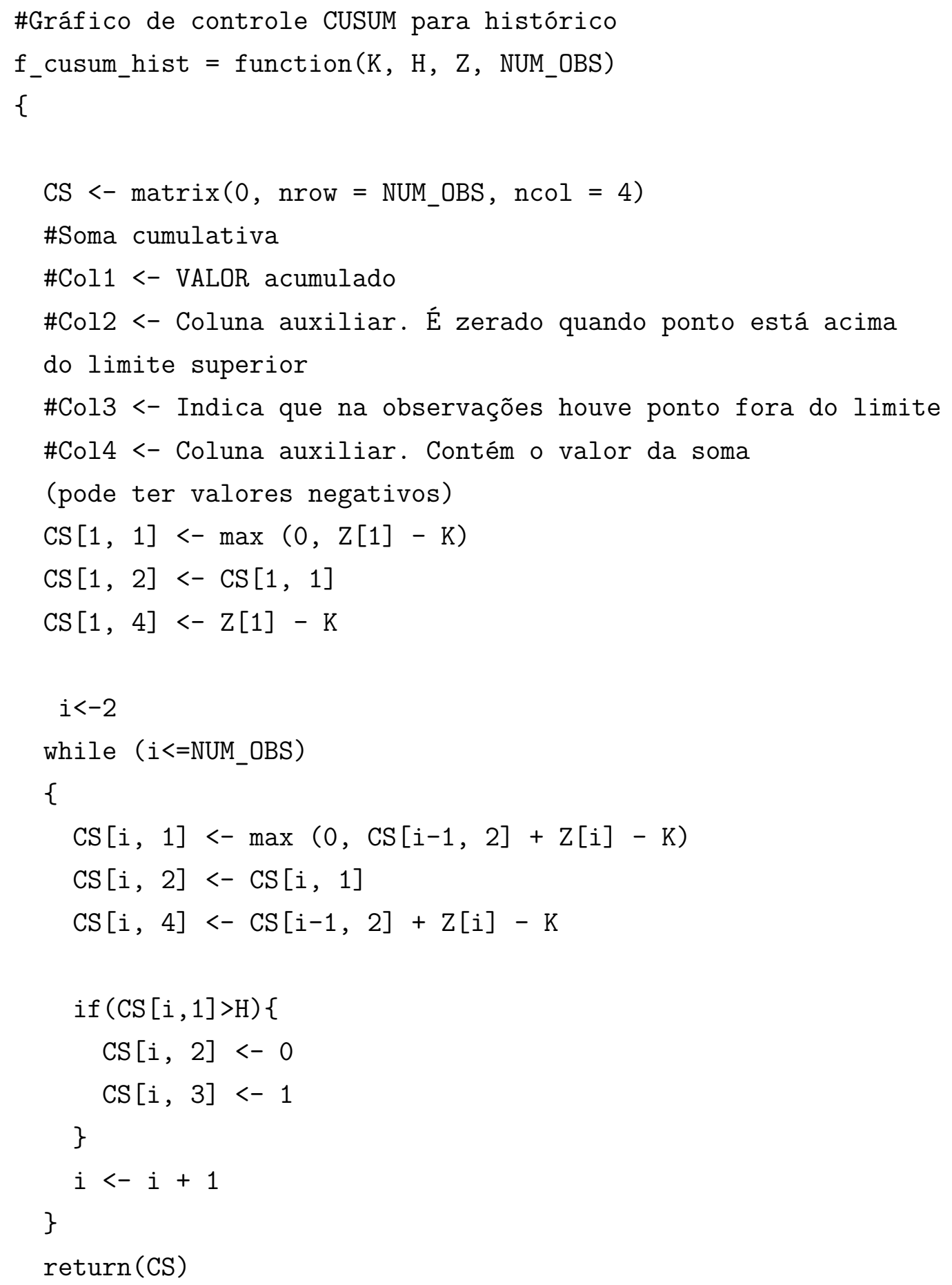

$\mathrm{f}_{-}$cusum06_hist $=$function $\left(\mathrm{Xt}_{-} \mathrm{K}, \mathrm{H}, \mathrm{C}, \mathrm{NUM}\right.$ _OBS $)$

\{

CS <- matrix $(0$, nrow $=$ NUM_OBS, ncol $=4)$

\#Soma cumulativa 


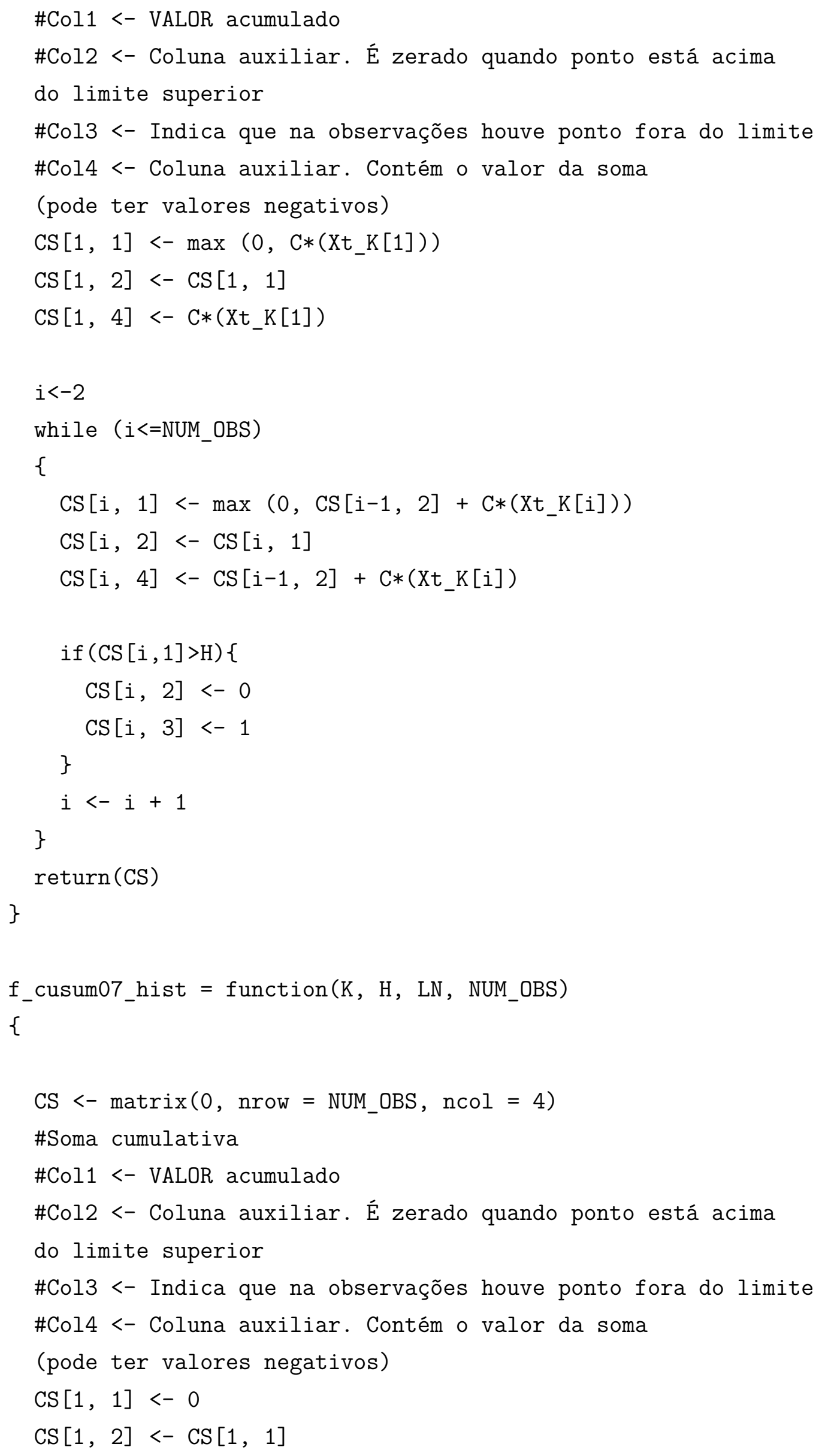




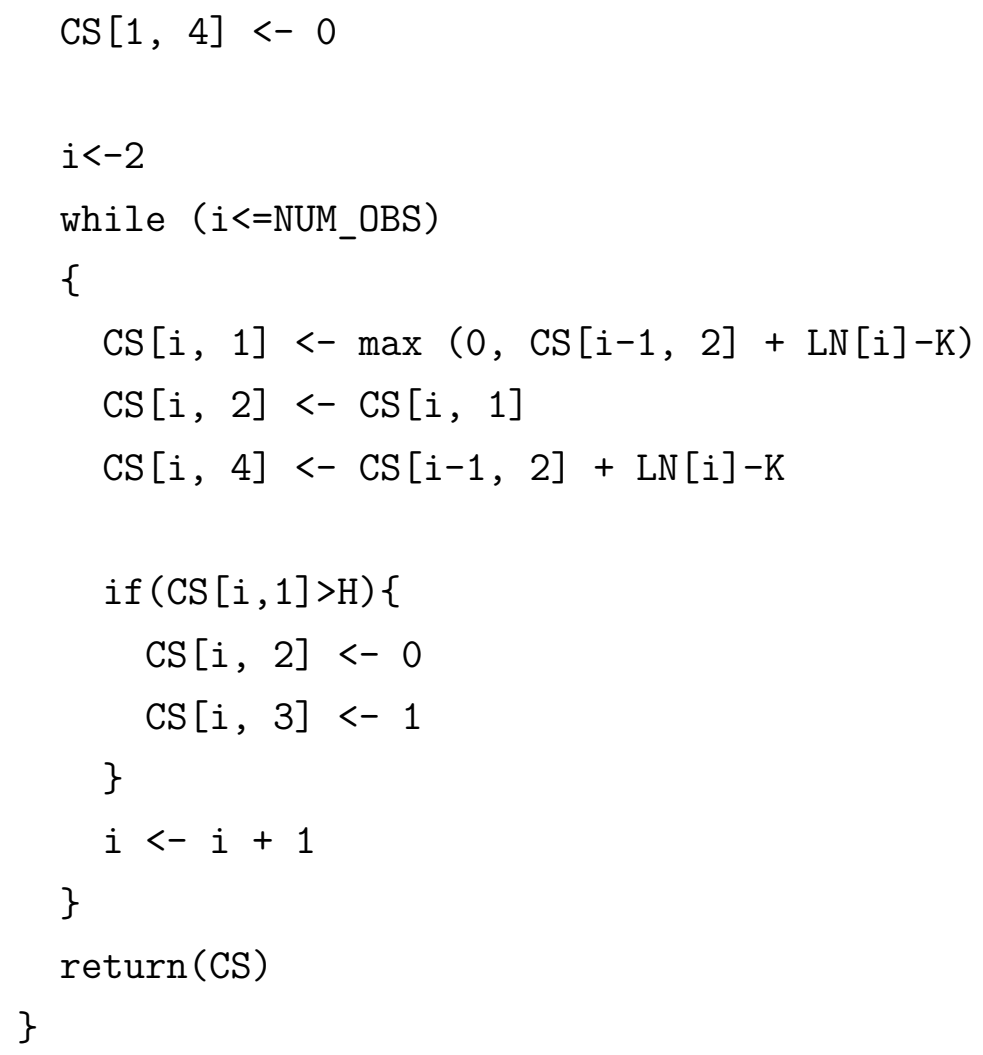




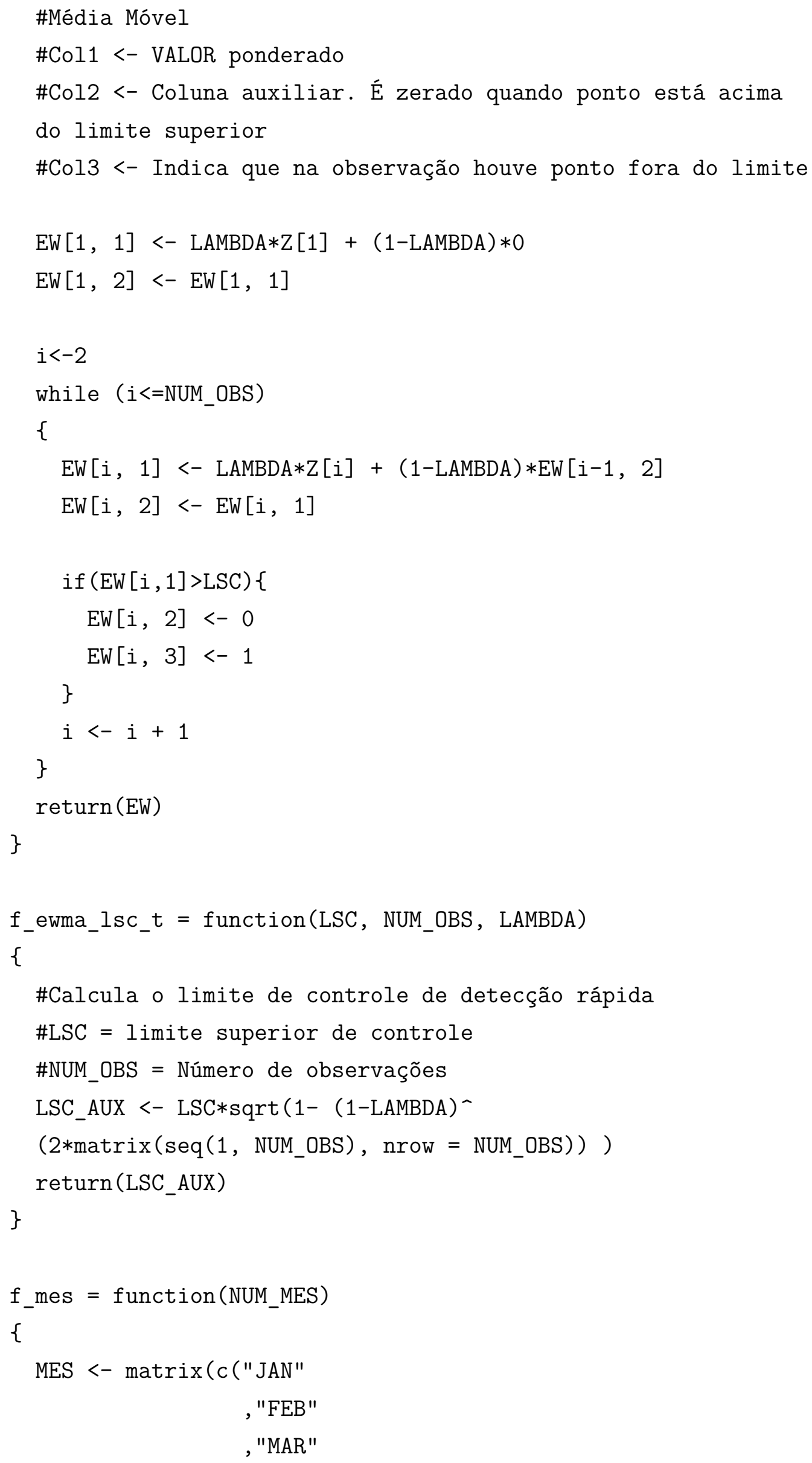




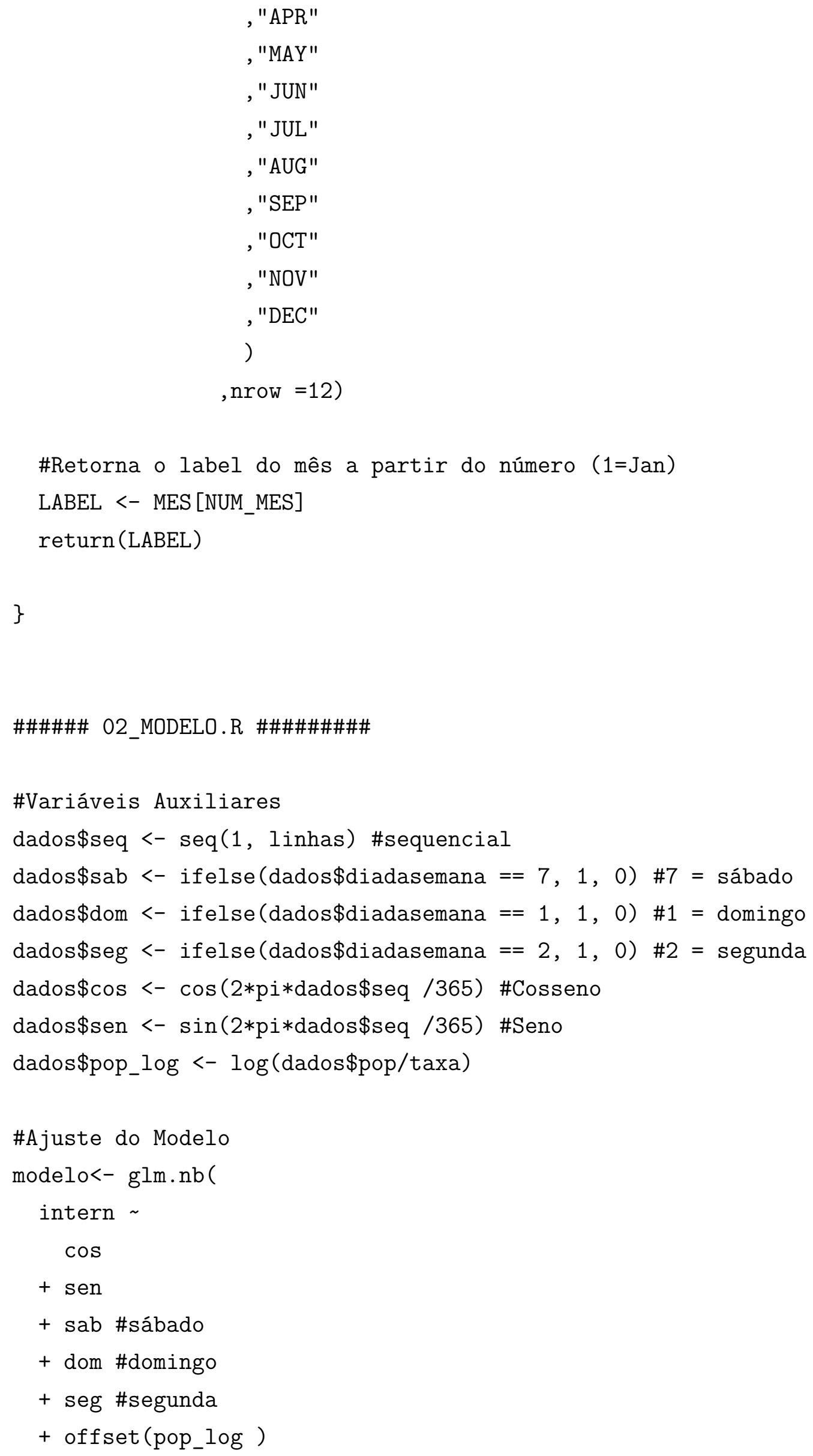




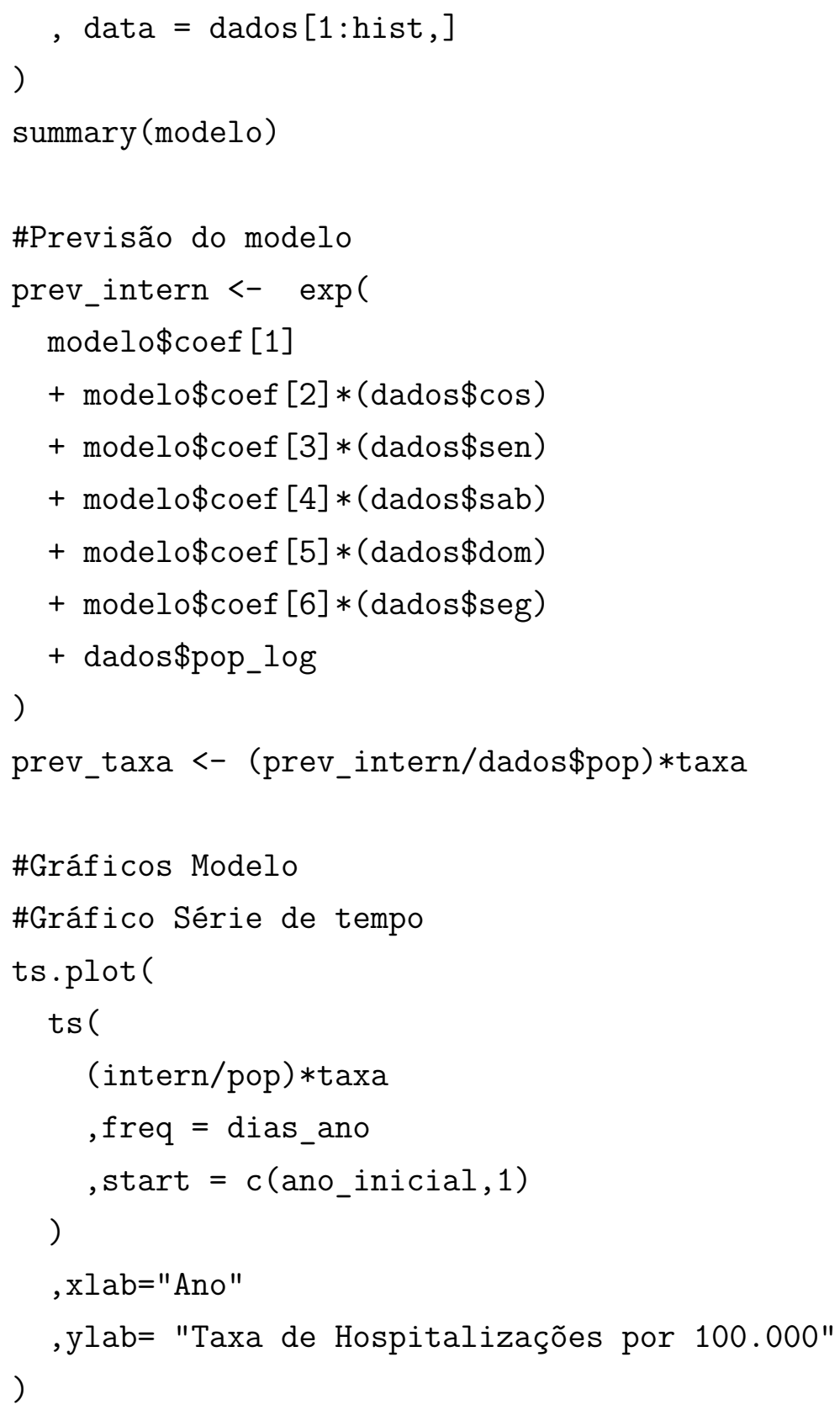




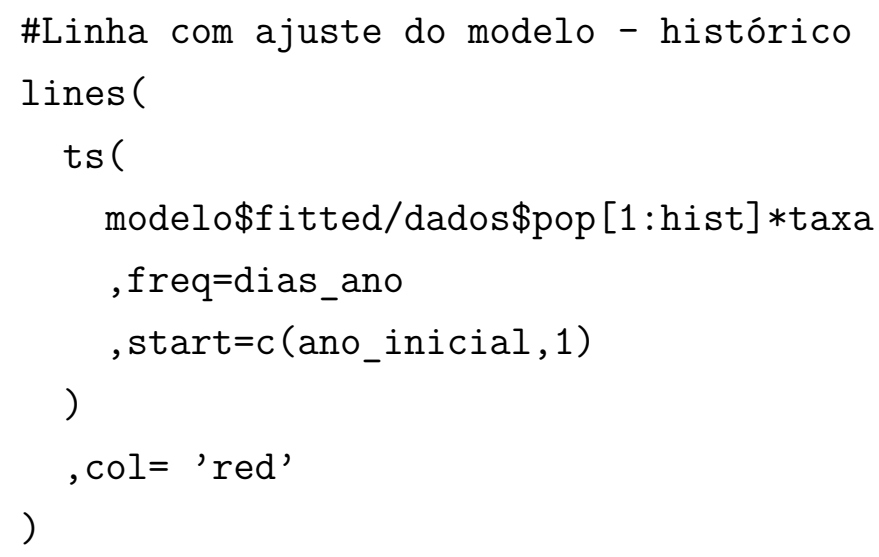




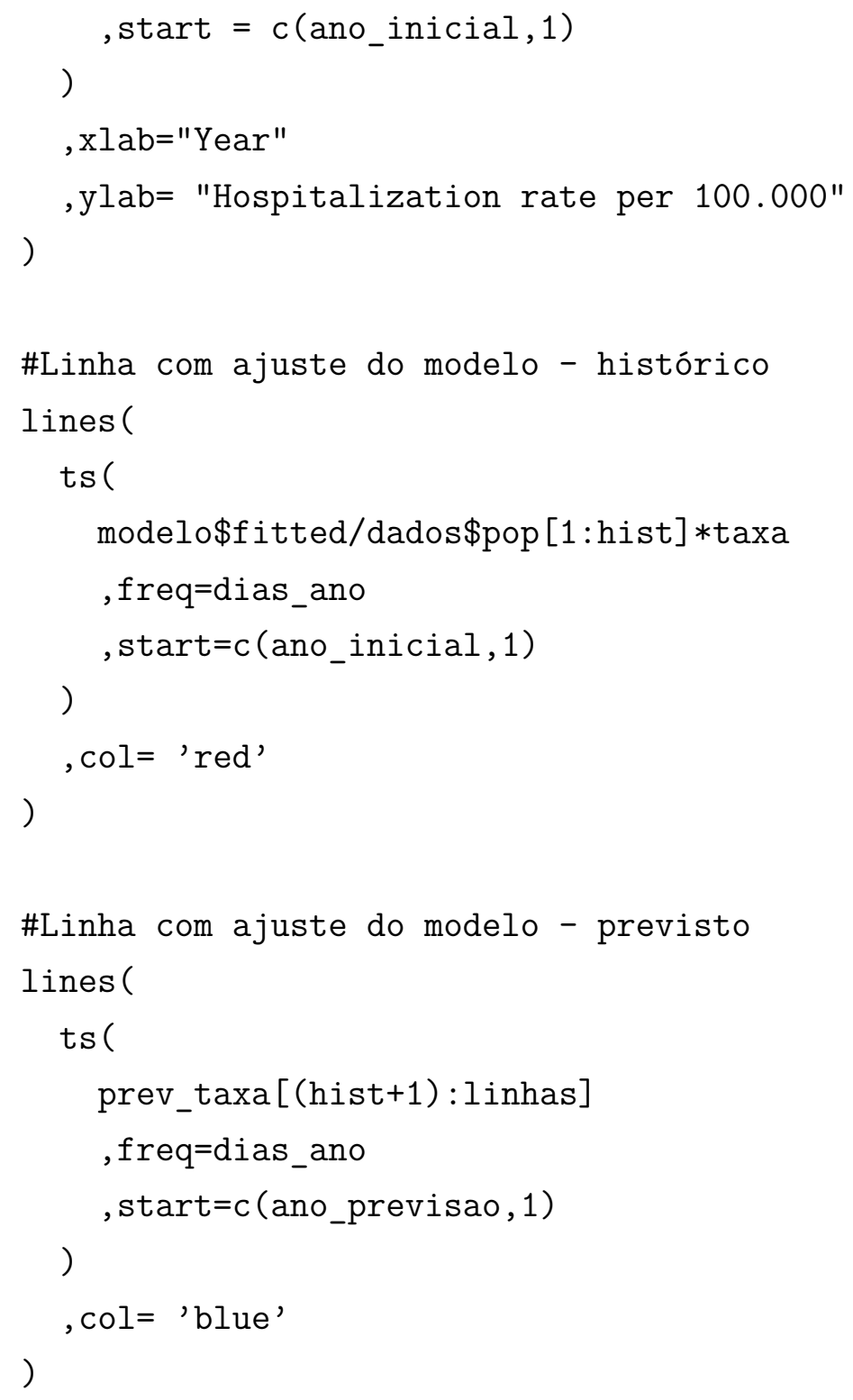




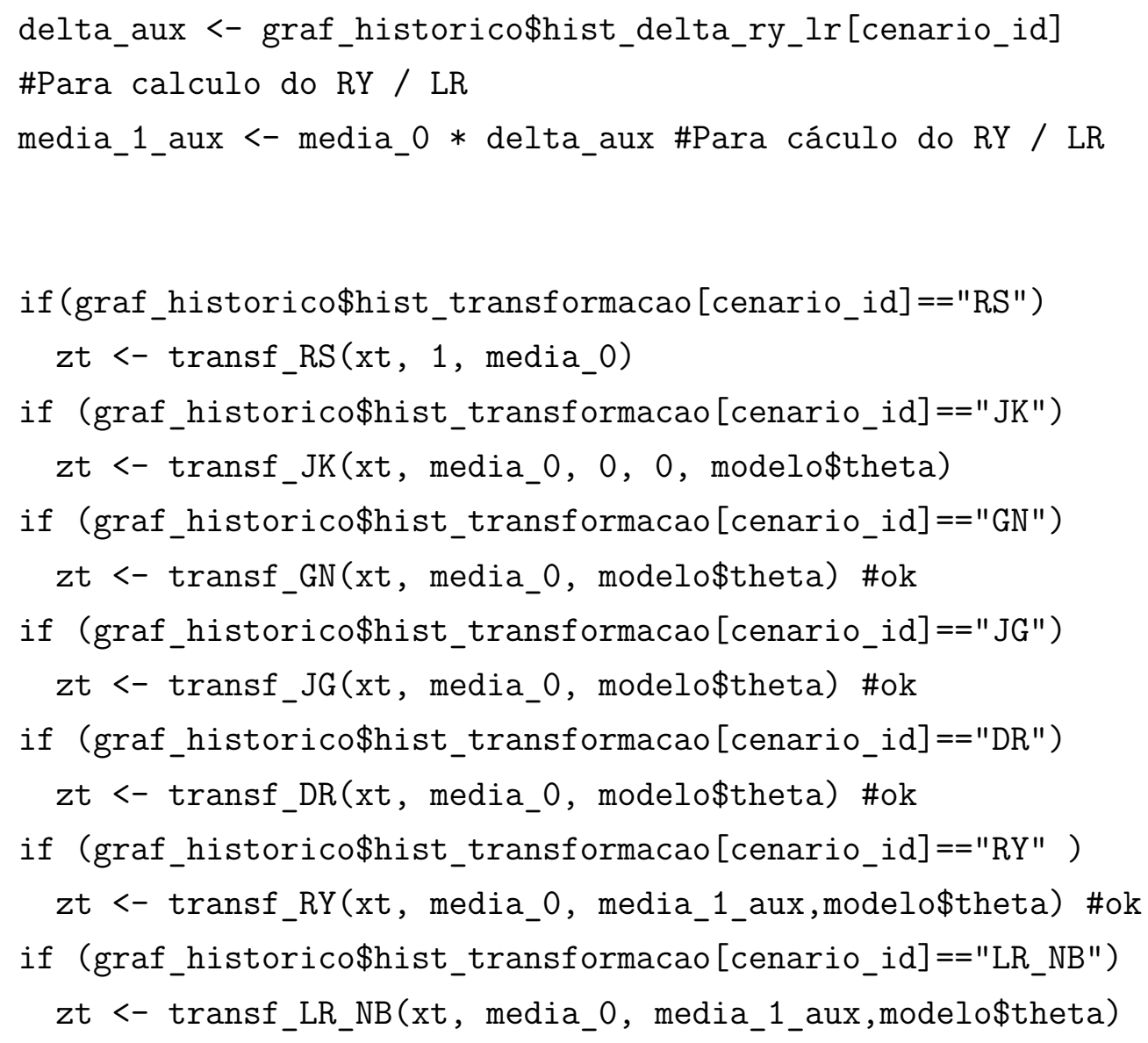

if (graf_historico\$hist_transformacao[cenario_id]=="LR_NB") \{ label_y = "LR"

\}else

label_y = graf_historico\$hist_transformacao[cenario_id]

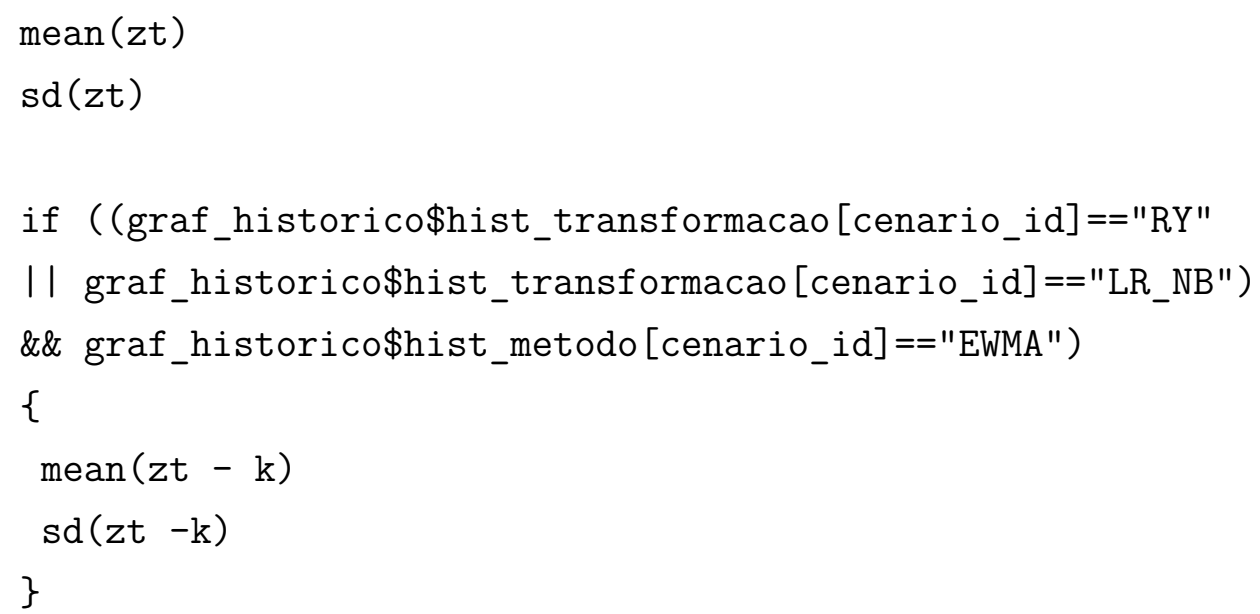




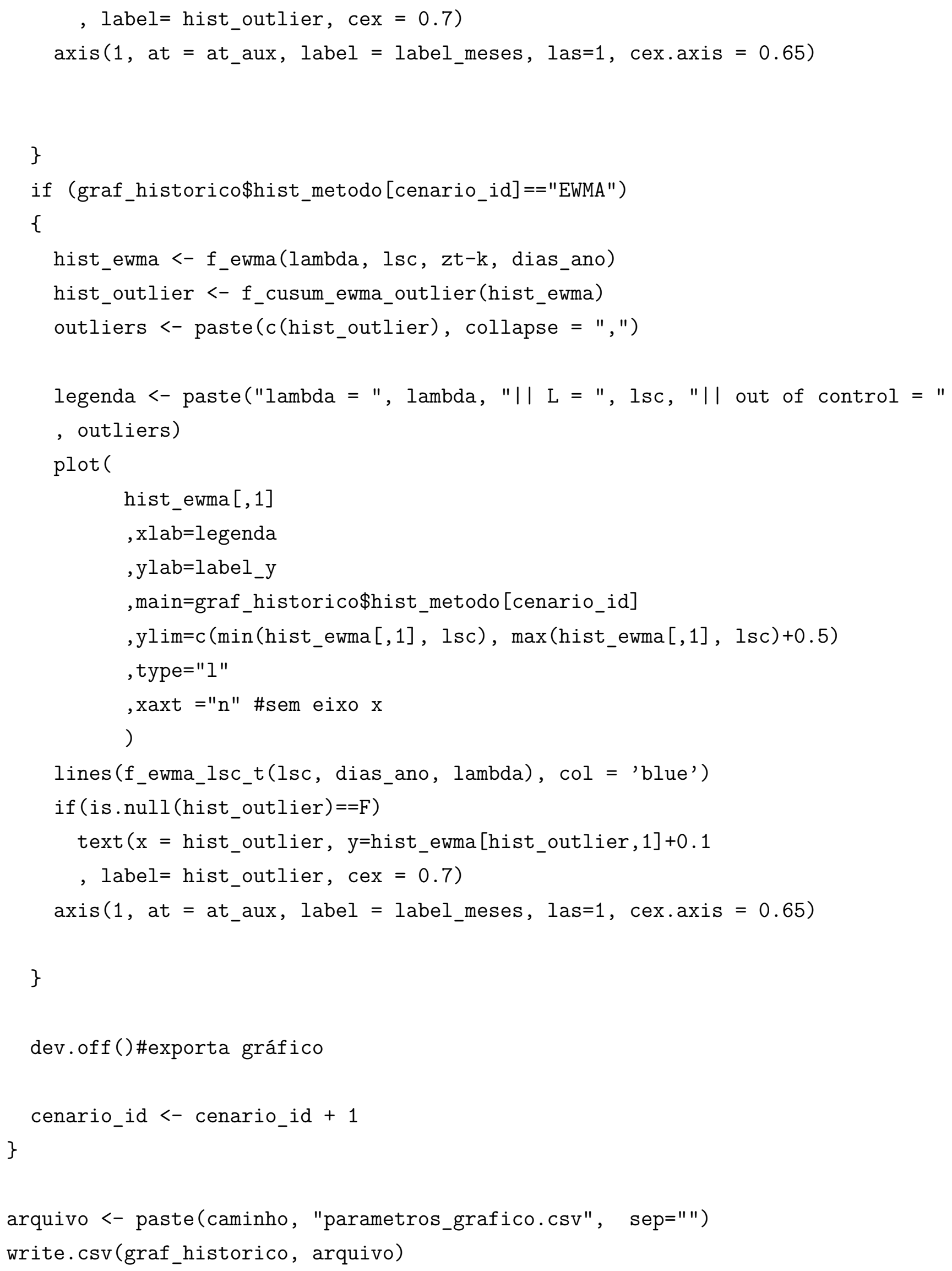




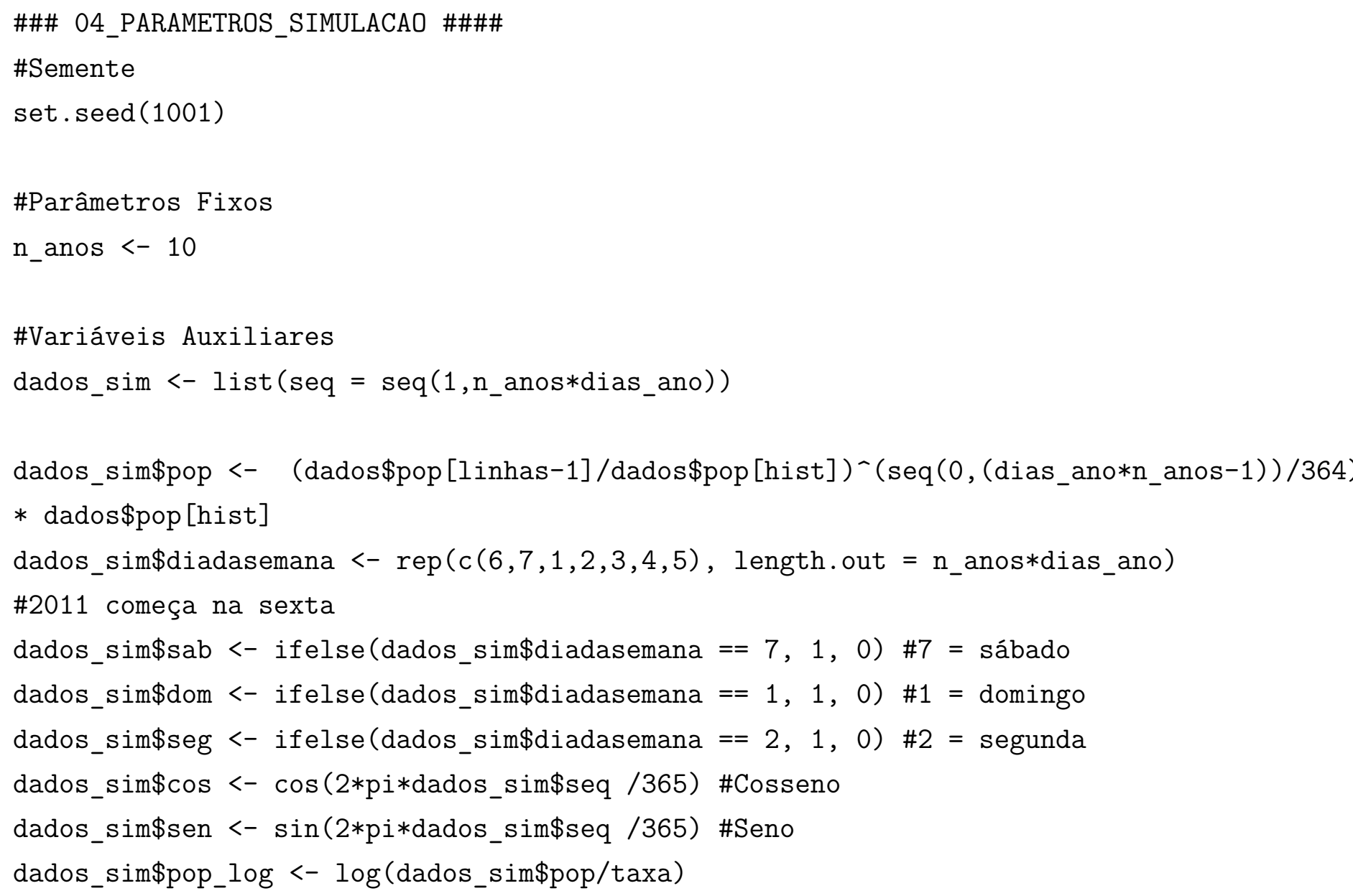


\#\#05_CENARIOS.R

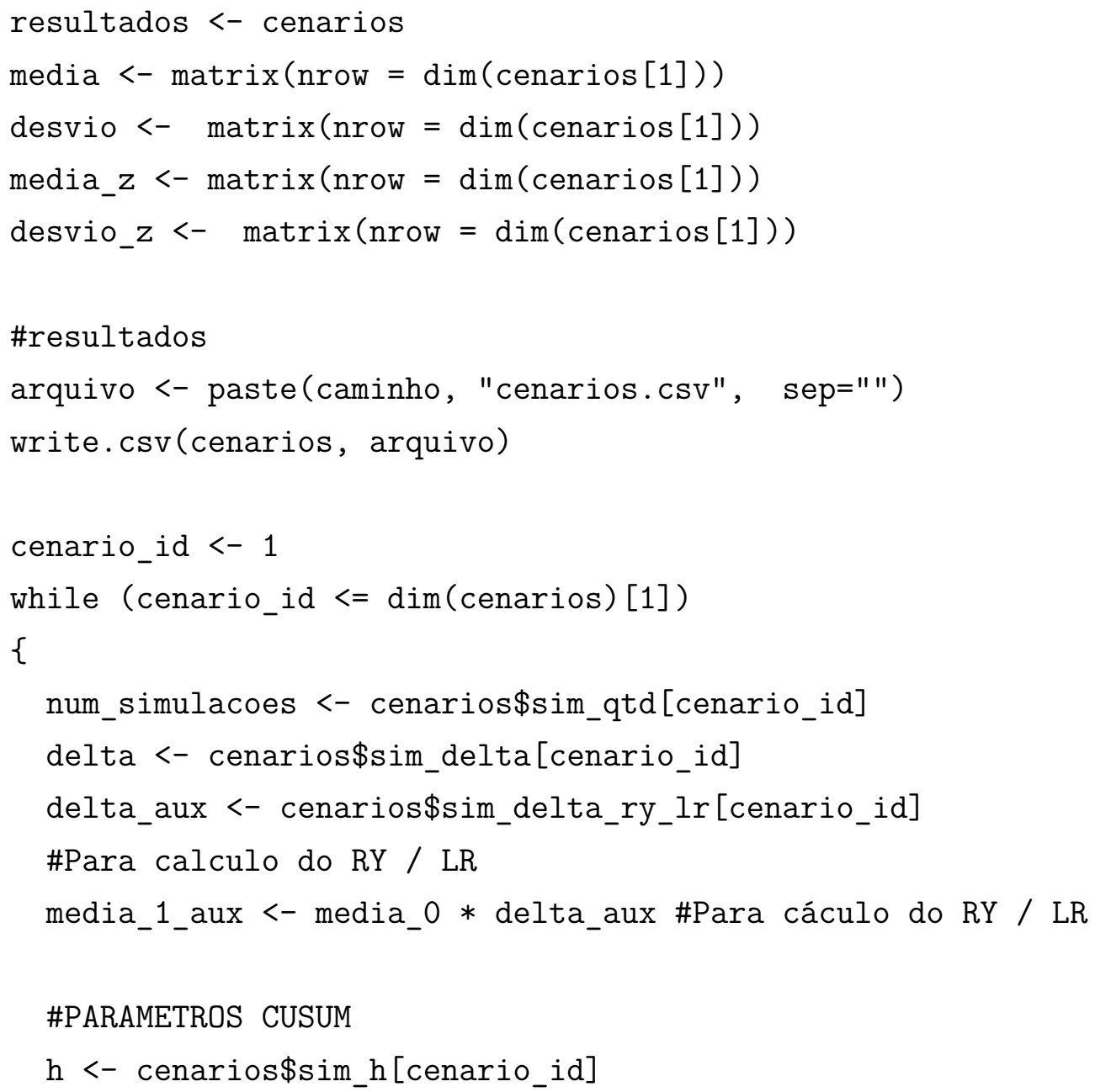




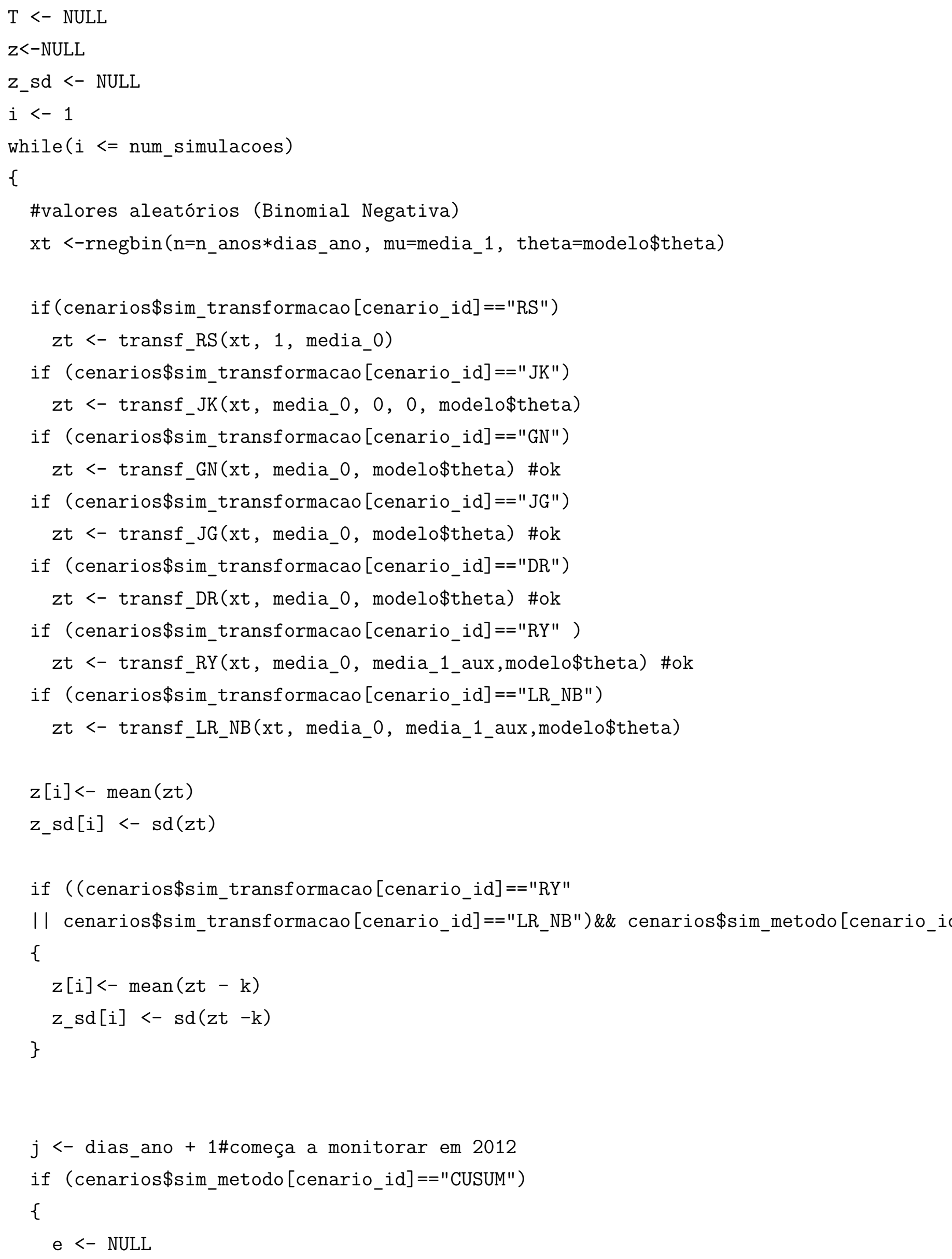




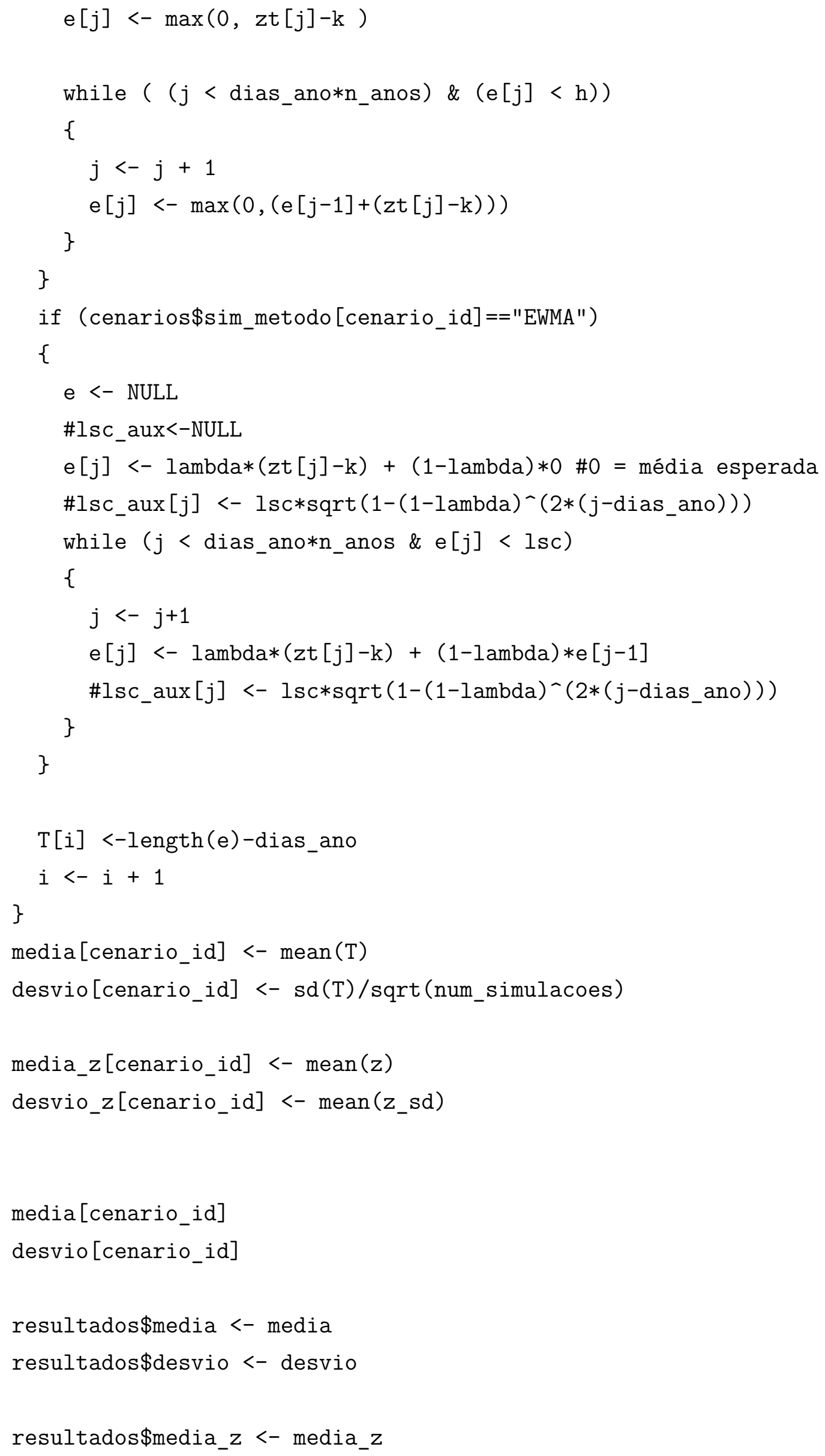




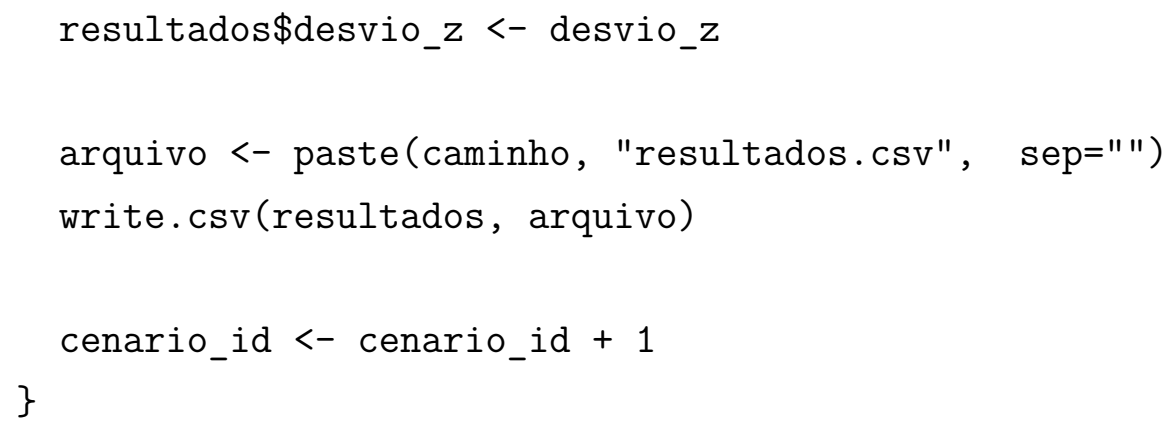




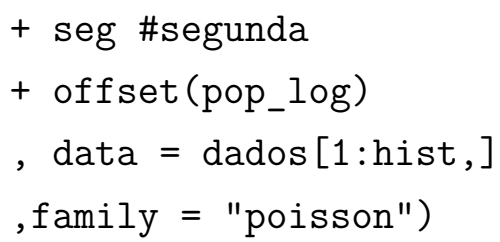

\#Gráfico de Resídulos

res_poisson <- resid(modelo_poisson, type="deviance")

qqPlot (res_poisson, ylab="Resíduo da Desviância"

, $\mathrm{xlab}=$ "Quantis gaussianos", main = "Poisson")

qqPlot (res_poisson, ylab="Deviance residuals"

, $x l a b=" G a u s s i a n$ quantiles", main = "Poisson")

shapiro.test (res_poisson)

summary(modelo_poisson)

\#teste de sobredispersão

library (pscl)

odTest (modelo) 